\title{
Sikh Males In Ontario And Random Police Stops (Carding)
}

\author{
By \\ Gurdeep Singh Jagpal
}

A Thesis submitted to the Faculty of Graduate and Postdoctoral Affairs in partial fulfillment of the requirements for the degree of

Master of Arts

In

Legal Studies

Carleton University

Ottawa, Ontario

(C) 2018

Gurdeep Singh Jagpal 


\begin{abstract}
This thesis is based on interviews with Ontario adult Sikh males who have had carding experiences. The participants' responses indicate that discrimination occurs towards Canadian Sikh males, including institutional discrimination. During their carding experience, the Sikh males were usually given either a made-up traffic violation reason when they were driving, a false investigative reason when they were on the street, or no reason at all to stop them. A good portion of the participants also faced a random search of their vehicles and/or of themselves during their carding incident. In exceptional cases, Sikh males faced an abusive experience. Thus, the participants view carding as a practice that targets their communities. I argue that carding has negative impacts towards Sikh males, including impacts on their psychology, future opportunities, and their evaluation of Canadian police officers. Participants provide that police conduct towards their communities needs to improve.
\end{abstract}




\section{Acknowledgments}

This project was made possible by the unwavering support of many individuals. I am grateful for everyone's contribution to this project, as this project would not have been possible otherwise.

First off, this project would like to thank UNITED SIKHS for their commitment to this project. UNITED SIKHS is committed to making a world a more equitable place, which was evident from their staunch support in projects such as this one. Their guidance and help, such as the use

of office space, will forever be cherished. For more information, please visit: https://www.unitedsikhs.org/

For my thesis supervisor, Dale Spencer, thank you so much for being apart of this long journey. Your expertise and guidance has transformed this thesis project from a discussion to what it is now. I am forever grateful for everything you have done in this project.

For Jeffrey Monaghan and Richard Mann, thank you for your fantastic comments and revisions to this project. It is an honour and privilege to learn from two individuals who have done great things for the community. I appreciate your contributions and unwavering support.

To all my family, friends, and colleagues who have contributed to this paper, whether it be by their guidance, edits, sharing my project's poster, practice interview simulations, motivational words, etc., thank you. Each one of your contributions played a significant part in this project is much appreciated.

To community groups and members of the Sikh and South Asian communities, thank you for your support in this project. Whether it was granting permission to post on their websites, such as the South Asian Legal Clinic of Ontario, permission to hang posters in local Gurdwaras and community businesses or just local support from individuals, it was meaningful. I value all of the support.

I am also grateful for every individual and group that gave me the opportunity to present my project on their platform. So far this includes live interviews with Tehlka Media, Hamdard Media Group, and guest lectures at Carleton University for professors Madalena Santos, Jeffrey Monaghan, and Darren Pacione. Thank you for sharing your time and space.

And finally, but most importantly, I would like to give a huge thank you to every individual who was a participant in this project. It can be difficult for an individual to want to share their carding experience due to the nature of carding towards the South Asian community. It is very courageous for a participant to share their story and this project would not be possible without their participation. Each story has a unique place in this project and is essential for the understanding of how Ontario Sikh males were impacted by this practice. Thank you so much for being apart of this study. 


\section{Contents}

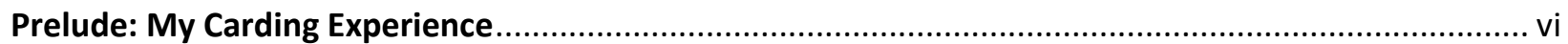

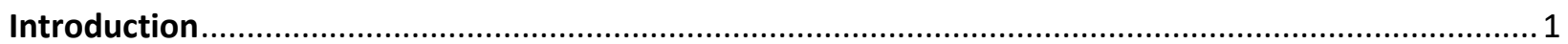

Chapter 1: Literature Review: The Sikh Diaspora And Racial Profiling ............................................... 7

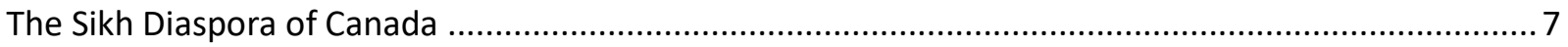

Episodes That Impacted The Canadian Sikh Diaspora ....................................................................... 8

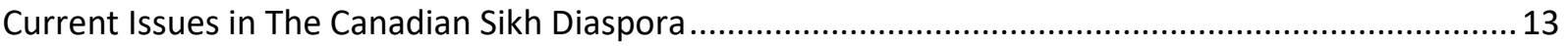

Racial Profiling And Bias: The Overrepresentation of Minorities ...................................................... 15

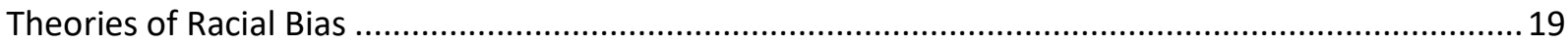

Conclusion: The Racial Profiling Practice of Carding and The Sikh Diaspora .......................................23

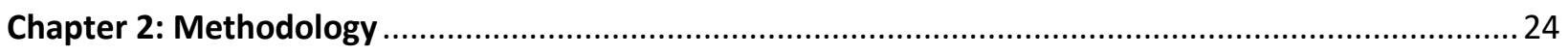

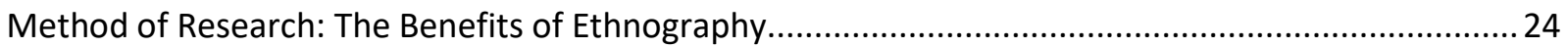

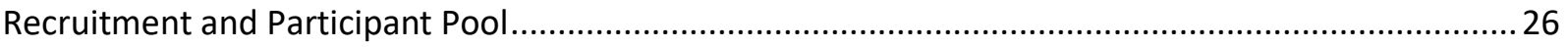

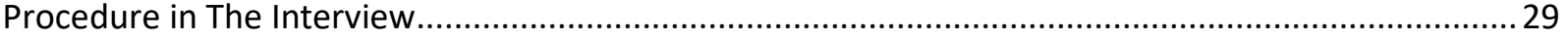

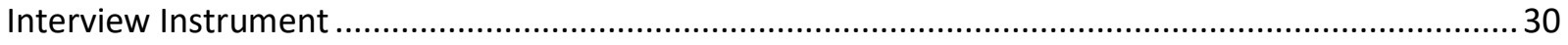

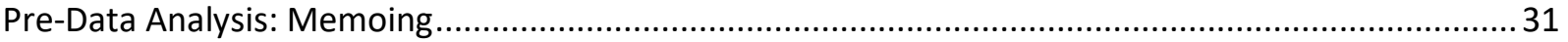

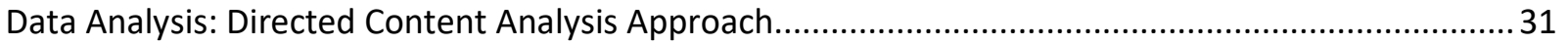

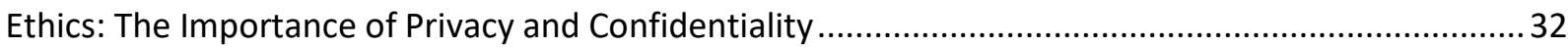

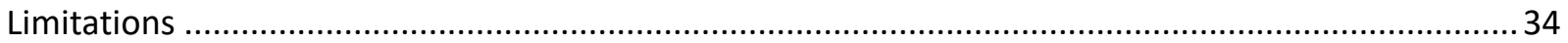

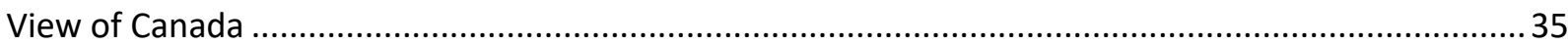

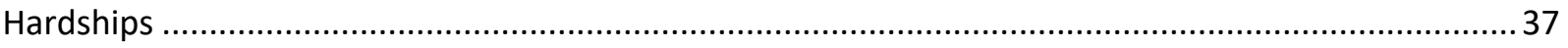

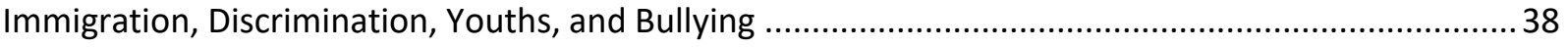

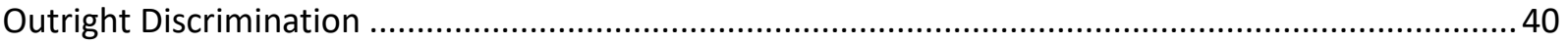

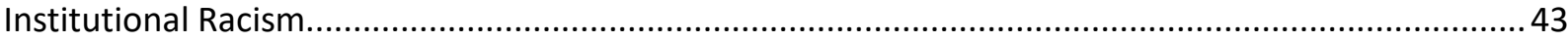

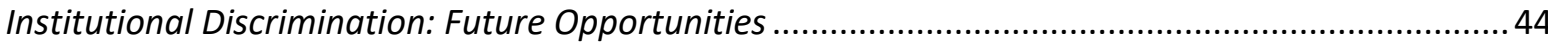

Institutional Discrimination: Treatment by Services and Organizations........................................ 47

Conclusion: Discrimination is an Issue in The Sikh Community ...................................................... 51

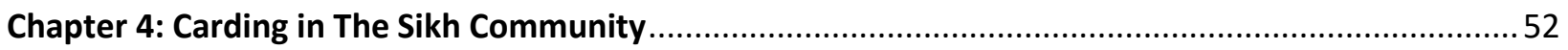

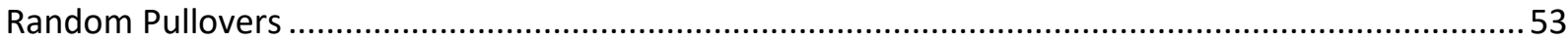

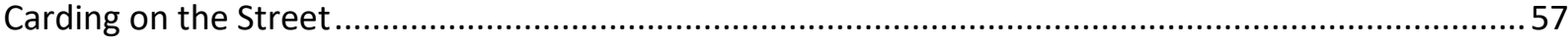

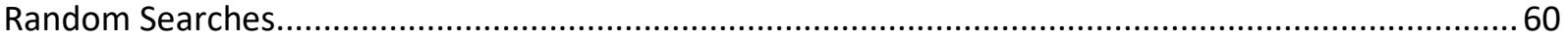

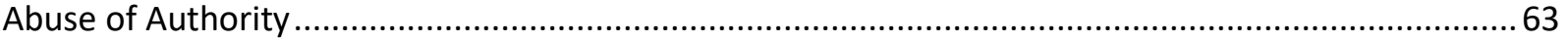


Conclusion: Carding And The Broader Sikh Community ..................................................................67

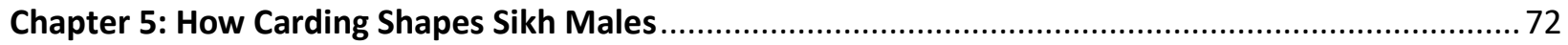

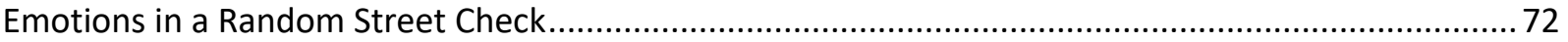

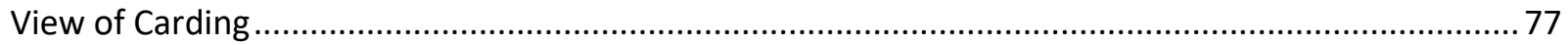

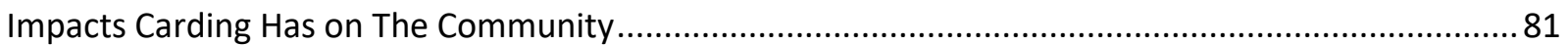

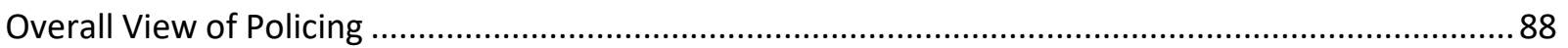

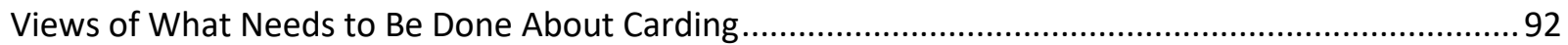

How Canadian Sikh Males in Ontario Are Affected by Random Police Stops...................................... 98

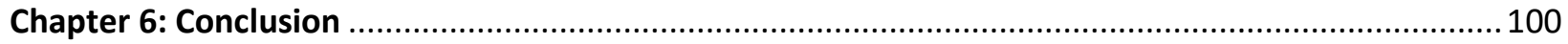

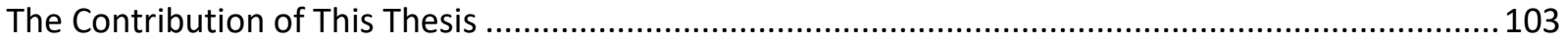

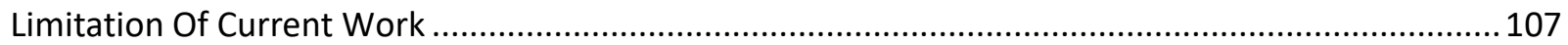

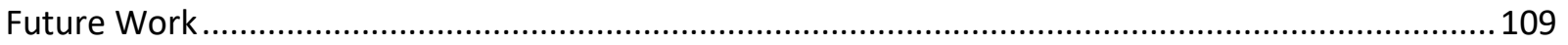

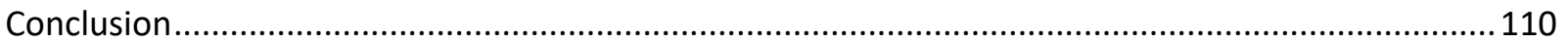

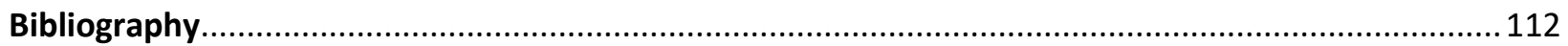




\section{Prelude: My Carding Experience}

- when the driver asked why he was pulled over, the officer said, "you will figure that out when you go to court."

I chose to conduct Sikh Males In Ontario And Random Police Stops because stories of Sikhs and random pull overs arise in the community. No prior research project has documented the Sikh community's stories; thus, the broader community does not know of our experiences. I have also faced a carding incident with a friend, which inspired me to pursue this project. We both identify as Sikh. Below is my story of being carded and how it prompted me to pursue this thesis project.

On the morning of February $25^{\text {th }}, 2015$, me and my friend were randomly pulled over by two police officers. The two Peel police officers were driving in the opposite direction of us. Upon noticing us they changed direction, followed, and pulled us over, almost immediately. Two

young White officers stepped out of their police vehicle. The first officer came to the driver's side and the second officer came to my side of the car. The first officer never informed my friend the reason of the pullover. When the driver asked why he was pulled over at the end of the police interaction, the first officer said, "You will figure that out when you go to court." When I asked the second officer the reason for our pull over, he directed his attention to me and said, "We have reason to believe the driver was drinking and driving." The second officer also claimed that he smelled alcohol from the vehicle. The officer's allegation was false as I do not drink alcohol and the driver stopped drinking alcohol for a month and a half.

The two officers left for their vehicle, and once they returned, told us both to get out of our car. They separated us, gave each of us a pat down, and forced us to empty our pockets. The first officer gave my friend a pat down while the second officer gave me a pat down. After the pat down, the second officer asked me, "Are you both hiding something? Tell me now, and you 
both will go off easy. I had seen you both moving in the car, what are you both trying to hide." I replied with, "what are you talking about?" Then suddenly, I heard the first officer screaming at my friend, "What are you fuckin hiding! I know you are hiding something, what are you fuckin hiding!" The second officer told me to stay where I was while he went to help the first police officer. They were very aggressive towards my friend and forced him into the back of the police cruiser.

After forcing my friend into the police cruiser, the second officer now started to walk towards the car and said, "I have reasonable grounds to begin searching the car." I knew the officer did not have reasonable grounds to search the car and I attempted to prevent the officer from searching it. I began to tell the officer that I am currently studying my undergrad in Law and Society and I know that you can't, but the officer cut me off when he angrily said, "Shut up! Don't talk to me like that. I am an officer, and I know what I am doing” and so forth. By the end of the police interaction, the first officer found a gram of marijuana on my friend and charged him with possession of marijuana. The second officer said to me, "we usually would not charge for such a small quantity of marijuana; however, you guys were very rude and were not complying, so your friend will be charged with possession of marijuana."

Approximately a year and a half after the incident, my friend called me to inform that he needed me as a witness. My friend and I were shocked to find out this had become a court case. My friend's lawyer had a similar reaction and called this, "a nothing case." The trial was for possession of a trivial amount of marijuana, which was found by unconstitutional methods.

When we first entered the courtroom, we found a group of high school students sitting in the audience section for their field trip. The Crown's lawyer told the students: "now kids, you might see someone go to jail today." I was upset to hear that, as my friend should not have been 
on trial for this charge initially. If my friend were convicted, he would have a criminal record, and that would drastically impact his future.

As I was the witness, I was not allowed in the courtroom once the case began. I was not called back to the courtroom, as the crown offered to drop the charges. The offer was conditional as my friend had to complete 35 hours of community service by a specific period. My friend's lawyer said, "though you are most likely going to win this case, it is better that you take this deal because it's guaranteed."

According to my friend, the crown offered this deal because the police officer was nervous on the stand and gave bad responses to his own lawyer's questions. The officer also provided false information about the pullover. The officer claimed that he followed us for five minutes, that we were driving suspiciously, and that we were swerving back and forth between lanes. At this point of the trial, my friend's lawyer did not question the police officer yet. The crown felt that they were going to lose the case and thus offered my friend the deal.

Overall, this incident had negative consequences. The case impacted my friend financially. My friend had to pay for a lawyer, had to take time off work to come to court, and lost thirty-five hours of his time towards community service. In total, he lost a few thousand dollars. Our incident depicted to us that there is racial bias in the criminal justice system. If the crown were victorious in this case, it would have negatively impacted my friend's future. My friend hired a good lawyer but what if he could not afford a lawyer? It can be difficult to get legal aid representation, due to legal aid underfunding. Many racialized individuals are low income and need to use legal aid. What if the police officer was a good liar? The officer that we had was young and appeared inexperienced in court proceedings. If the officer was a good liar and was confident in court, the crown could have potentially won that case. All these scenarios 
made me wonder, how police practices impact racialized minorities. If I could have a lousy experience towards carding, then there is a good chance others in the community may have faced it as well. My carding experience motivated me to pursue this thesis under the title Sikh Males In Ontario And Random Police Stops. 


\section{Introduction}

Having committed no offense, while under no specific investigation, police have stopped me eleven times in my life. The first time when I was seventeen. I remember the early stops involved "routine investigations" while driving my father's car. I had committed no offense \& received no ticket, but the experiences left me shaken and confused. More troubling it left me asking what it was about me the police felt was dangerous and criminal. It made me question my self-worth.

-Jagmeet Singh (@theJagmeetSingh), Federal NDP Leader

Jagmeet's quote reflects experiences Canadians encounter due to the controversial police practice of carding ${ }^{1}$. Carding is when police officers stop one or more civilians and ask those individuals for their IDs. The officers question those individuals and record their information into a police database. This process can occur while the civilian(s) are walking on foot, riding a bicycle or driving a vehicle. The data is later used by the police to find potential leads to criminal activity. In most of these circumstances, the civilian, has not broken any laws. Different police agencies and police spokespersons, such as Mike McCormack, the president of the Toronto Police Association, claim carding to be a useful investigative tool which reduces crime (The Agenda with Steve Paikin, 2015). Racial minority groups, such as Black Lives Matter, argue carding is a racist policy that is used to monitor and harass their communities (Reiti, 2016). Howard Morton (2015), a lawyer with the Law Union of Ontario, claims carding is a constitutional violation of an individual's rights, as many individuals are forced to comply because of intimidation. Because of the controversies surrounding carding, the Government of Ontario created new carding regulations called Reg. 58/16: COLLECTION OF IDENTITY

\footnotetext{
${ }^{1}$ Carding can be referred to a variety of different names such as Street Checks, Street Intelligent Reports, or Community Contacts Policy, based on the city.
} 
INFORMATION IN CERTAIN CIRCUMSTANCES - PROHIBITION AND DUTIES. These regulations began on January $1^{\text {st }}, 2017$.

Carding is still controversial as Canada has a history of racial bias in the criminal justice system. Wortley (2003), as well as Close and Mckena (2006), argue Black Canadians are more likely to be monitored and questioned by the police than any other group. This disparity happens because police officers often profile, in which officers first find a suspect, and then search for the crime (Tator and Henry, 2006). A Black Canadian is more likely to be profiled because of negative stereotypes associated with race (Tatar and Henry, 2006). Due to these surveillance practices, a Black Canadian is more likely to be caught conducting a criminal activity than another racial group in Toronto (Wortley, 2003). The success of these surveillance methods such as carding is controversial. No data has been released to demonstrate whether carding solves crimes in Canada. Data towards the success of the stop and frisk program in New York City, a program similar to carding, has been released. According to a report conducted by the Center for Constitutional Rights, the stop and frisk program had minimal success in finding weapons and contrabands (Krupanski et al., 2009). Latinos and Black Americans made up 80 percent of the total stops, though both groups represented just fifty-three percent of New York City's population (Krupanski et al., 2009). This policies' success in solving crimes is not proportional to discrimination minority groups face.

Although no data is available to prove whether carding reduces crime despite its widespread usage, information is available to prove racial bias exists in this police practice. Rankin and Winsa (2012) of the Toronto Star analyzed the Toronto Police Service's carding data. Their analysis revealed that Black and Brown civilians are more likely to be carded then other civilians (Rankin and Winsa, 2012). From 2008 to 2011, the police carded 3.4 times the 
young Black male population of Toronto, and the police carded 1.8 times the young Brown male population of Toronto. In comparison, the police carded 1.0 the young White males population of Toronto (Rankin and Winsa, 2012). Furthermore, Meng (2017) argues Black Canadians are more likely to be carded in all areas of Toronto. Black Canadians are especially more likely to be carded in areas of Toronto with a high crime rate and in areas with a significant White majority (Meng, 2017). Thus Morton (2015) argues carding impacts youths and the marginalized more than any other group. From the review of the literature, carding is a policy that disproportionately targets racialized minorities.

Due to the controversaries surrounding police practices, Justice Tulloch, an Ontario Court of Appeal judge, was assigned to analyze police practices on two separate occasions as an independent reviewer. His first review was called Independent Police Oversight Review and the second review was called The Independent Street Checks Review. In both reviews, Justice Tulloch had consulted the public and independent stakeholders towards police practices. The first review led to the creation of Bill 175, which would have improved accountability measures. For example, the SIU director would have more powers to investigate offences committed by officers and would have more mechanisms in place to ensure officers comply with the investigation, such as large fines of $\$ 25,000$ for first offences. The Independent Street Checks Review concluded with many recommendations against the police practice of carding, such as that police officers should not be arbitrarily stopping individuals. However, the current Ontario Progressive Conservative (PC) Government argued Bill 175 prevents police agencies from doing their job and have thus delayed its implementation. Also, the PC government has refused to ban carding last time a motion was introduced to ban the practice. From groups that represent racial minority interests, not enough has been done to prevent carding. 
The Sikh community of Canada faces a prevalence of racial bias due to negative views associated with the community. In a poll conducted by Angus Reid in 2009, only 30 percent of Canadians had favorable opinions of Sikhs (Todd, 2009). Views of Sikhs include violent, terrorist, and a national security threat (Ahluwalia, 2013; Mann, 2017; Walton- Roberts, 2016). Government institutions commonly use profiling practices to monitor the feared Sikh body (Paur 2008, Mann, 2017; Sian, 2017). In airports, Deal (2011) argues Sikhs forfeit their civil liberties when they fly on planes for the name of national security. Removal of turbans, extra pat downs, and secondary screenings are common (Deal, 2011; Sian, 2017). Furthermore, Sian (2017) argues Sikhs face increase instances of profiling, policing, tracking, stop and search practices, and interrogation after the catastrophic events of 9-11. Racially biased views of Sikhs led to negative implications towards the community.

Some of these negative instances of profiling include the prevalence of the police practice of carding. Some Sikhs, such as the NDP federal leader Jagmeet Singh, can identify carding stories. Jagmeet Singh was carded by the police eleven times in his life. In one of his experiences, two officers carded Singh at Casa Loma, which is in Toronto. At the end of the interaction, the two officers had called for a Sikh police officer who wore a turban (Lum, 2017). The Sikh police officer explained to Singh that his carding incident was not because of racism but was instead a routine procedure. In Singh's words, “The fact that they had to call a Sikh man to tell me that it wasn't [carding] just really highlighted how much it was (Lum, 2017)." Ethnicity was a culminating factor in both the incident and the explanation. Singh's carding experiences negatively impacted him as it made him question his self-worth (Singh, 2017). Controversies around carding towards Sikhs is evident in media outlets. San Grewal (2015) of the Toronto Star stated that South Asian businessmen in the Peel Region commonly face random 
pullovers. These businessmen argue officers pulled them over because they drove nice cars (Grewal, 2015). The Sikh community represents a large portion of the South Asian population in the Peel region. Prominent figures within the Sikh community discussed problems towards the carding practices. The former VP at the World Sikh Organization Ontario, Prabmeet Singh Sarkaria, has said carding impacts Sikh youth and a ban of carding is a step in preventing racial bias (Sandhu, 2016). Prabmeet Singh Sarkaria is currently an Ontario progressive conservative MPP representing Brampton South. Thus, Sikhs face carding and the practice impacts the community.

Although carding has impacted the Sikh Community, there is a dearth of academic research on this matter. There is a literature gap towards Canada's police profiling practice of carding and impacts it has on the Sikh community. A project should address this literature gap as it will produce literature to the Sikh experience with carding. It is beneficial to the Sikh population, as Sikhs would gain an understanding of how carding effects the diaspora. It is helpful to policymakers, as it will further articulate knowledge on how police practices affect different groups. Lastly, it is useful to police agencies as it will produce literature towards how carding impacted the Sikh community's perception of the police.

The following thesis fills this gap in the literature by answering the research question: how do random police stops impact Canadian Sikh males in Ontario? This thesis conducted an ethnographic study to answer this question. This project interviewed Sikh men in Ontario who had been randomly stopped by the police, whether it was in a vehicle or on the street. In each of these instances, the individuals did not commit any traffic violations, were not involved in any criminal activities, or broke any laws. They were stopped by the police without an incident occurring. This project first questioned the participants about their overall experience of living in 
Canada to understand the issues that surround the Sikh community. Then the participants were inquired to recount their random pull over story or stories. Finally, this project quired for the participant's perception of their carding incident and policing in Canada.

This thesis divides into six chapters. Chapter one of this thesis reviews the current literature on the Sikh Diaspora of Canada and racial bias in policing. The first section of this literature review discusses the experiences of the Sikh diaspora. The second section discusses the impacts of racial prejudice in the criminal justice system and why this occurs. Chapter two examines the research design of this thesis. This thesis used an ethnographic and direct content analysis approach. Chapter three of this thesis addresses the Sikh experience in Canada. This chapter describes the participants' overall views of Canada and the hardships that they have faced. This chapter discusses racism towards Sikhs in the public and government institutions. Chapter four discusses the participants' experiences in their carding incident. The participants' experiences are vast and vary from one participant to another. Thus, four general themes were created to encapsulate the participants' overall experiences. They are carding while driving, carding on the street, random searches, and abuse of authority. Chapter five discusses the participants' overall views towards carding. This chapter discusses the participant's feeling of being carded, the view of carding, the impacts of carding, the view of policing because of carding and views of changes carding requires. Chapter six is the conclusion of this thesis. This chapter discusses limitations, future research, and summarizes the thesis. 


\section{Chapter 1: Literature Review: The Sikh Diaspora And Racial Profiling}

This thesis will first discuss literature towards the identity construction of the Sikh Diaspora. This literature review shall present: (i) who the Sikh diaspora of Canada is; (ii) significant events that impact the Sikh Diaspora and the Sikh response to these events; and (iii) discuss literature that describes issues that Sikhs currently face. This thesis will then discuss the criminological literature that deals with racial profiling and racial bias. The first part of this literature review examines the presence of racial profiling and racial bias towards Canadians. The second part of this literature review examines theories that describe why and how racial minorities are profiled.

\section{The Sikh Diaspora of Canada}

Canada has a large Sikh Diasporic community, with its own unique identity and cultural heritage. Canada has the largest Sikh population outside of India and is also the fastest growing diaspora. The Sikh diaspora, along with the Jewish diaspora, are the only two religious diasporas in the world (Kaur, 2012; Nayar, 2004; Tatla, 1999). Religion is important for the Sikh identity, as Sikhs trace their heritage to Guru Nanak, the founder of Sikhism (Tatla, 1999). Many Sikhs wear their five articles of faith, Kesh (uncut hair, often covered by a turban or a traditional scarf), Khanga (wooden comb), Kara (a special iron bracelet), Kirpan (a stylized representation of a sword) (World Sikh Organization, n.d.), and Kasahara (a special type of undergarment). Each article of faith has a special meaning, reminding a Sikh to the tenants of their faith. Different community members have different levels of faith, with some members wearing all articles of faith while others are wearing none (Nayar, 2004). The religious rituals and customs tend to be 
uniform across all Gurdwaras ${ }^{2}$ in different countries (Tatla, 1999). The Canadian Sikh Diaspora also has strong relations to their traditional homeland, the northern Indian state of Punjab (Kaur, 2012; Nayar, 2004; Tatla, 1999). Nayar, (2004) and Tatla (1999) discussed how Sikh communities globally have strong economic, social, and cultural ties to Punjab. The Sikh diaspora invests financially in Punjab while Punjab has much influence towards the Sikh diasporic culture (Tatla, 1999). Because of this connection, events that occur in Punjab has significant impacts on the whole diasporic community.

\section{Episodes That Impacted The Canadian Sikh Diaspora}

Three periods negatively impacted the Sikh Diaspora. The first period was the negative treatment the original Sikh migrants faced in Canada and colonialism in India. Kaur (2011) argues that Sikhs were forced to look for opportunities abroad because of the British rule in India. Colonialism led to job loss due to deindustrialization, family debt due to unfair tax codes, and deaths due to plagues and diseases (Kaur, 2011). Countries such as Canada gave Sikh males better opportunities to support their families in India. However, the original Sikh migrants in the early 1900's faced discrimination from Canadians and many restrictions in Canada, such as finding employment and decent housing (Nayar, 2004). Many Sikhs abandoned their cultural and religious attire, such as their turbans and beards, to make it easier to find work (Nayar, 2004). Johnson (2014) dictates how the Canadian government denied Sikhs entry into Canada because of Anti-Immigrant sentiments and more specifically, Anti-Asian sentiments by policies such as the continuous journey act. Anti-Asian sentiments were most evident when a 400-passenger boat of mostly Sikhs challenged Canada's status quo by stating they are equal subjects of the British crown. After a two-month standstill, the passengers were forced to leave Canada without

\footnotetext{
${ }^{2}$ Gurdwara is the Sikh's place of worship.
} 
adequate food, water, and supplies (Johnson, 2014; Johnson, 2005). Gill (2004), Judge (2003), Jakobash, Walton-Roberts (2016), and Tatla (1999) shared similar accounts. Judge (2003) argues that Canada liberalized their policies in the mid-1900's and onwards because it became a necessity. Canada needed a younger and larger workforce, which was not being met by European migrants (Judge, 2003; Mann, 2017). However, the sentiments of Sikhs as the migrant other are still prevalent today, even towards those Sikhs whose families have been in Canada for a few generations (Judge, 2003). Sikhs were forced to leave India because of economic instability caused by the British and the Canadian government denied Sikhs the opportunity to immigrate to Canada until their immigration became a necessity.

The second period, the events of 1984 in India had devastated the global Sikh Diaspora and impacted the collective conscious (Das, 2006; Dhillon, 2007; Grewal, 2010; Harjeet, 2010; Kunda, 1994; Nayar, 2004; Nijhawan \& Arora, 2013; Singh 2009; Tatla, 1999). The first event, Operation Blue Star occurred on June $7^{\text {th }}, 1984$. This event shocked the entire Sikh Diaspora (Kunda, 1994; Dhillon 2007). The Indian army invaded the Harmandir Sahib (Golden Temple), the holiest site for Sikhs, to flush out Jarnail Singh Bhindranwale and others who had taken refuge and openly armed the temple complex (Dhillon, 2007; Kunda, 1994). Before Operation BlueStar, news outlets reported that violent attacks were being committed in Punjab. Indians viewed Bhindranwale as being above the law in Punjab, based on his actions. Thus, Prime Minister Indira Gandhi called for operation Blue Star (Dhillon, 2007; Kunda, 1994). However, Sikhs viewed Operation Blue Star as a tragedy. Mann (2017) argues Sikh's were stereotyped as violent, irrational, anti-Hindu, and against the interest of India by the media, which the Indian government has influence over. The stereotypes justified the state-based violence of the Sikhs to the Hindu elite population of India (Grewal, 2010; Mann, 2017). The impacts of stereotypes are 
most evident in Kundu's (1994) comparison of Sikh's and non-Sikh's view of Operation Bluestar. In Kundu's study, almost all Sikh officers argued that Operation Blue Star should not have happened, that other methods should have been used, compared to their non-Sikh counterparts (Kundu, 1994). Some Sikh officers argued the actions of Indira Gandhi created Bhindranwale (Kundu, 1994). In contrast, Tatla (2006) argues India projected Bhindranwale as a terrorist. Bhindranwale was fighting for Sikh interests in India peacefully (Tatla, 2006). Operation Blue Star angered the Sikh Diaspora as Sikhs viewed it as an act of sacrilege, an attack against the Sikhs, destruction of Sikhism's holiest site, and many innocent civilians were killed (Dhillon, 2007; Tatla, 1999).

The second event of 1984 was the Sikh Genocide ${ }^{3}$. In response to operation BlueStar, Indira Gandhi's two Sikh bodyguards had killed her on October 31, 1984. From October 31 to November 3 of 1984, organized mobs killed thousands of Sikhs in India, specifically in Delhi (Das, 2006; Nijhawan \& Arora, 2013; Singh, 2009; Tatla, 1999). Rumors about Sikhs as killers, rapists, contaminating the water supply were prevalent to scare the Delhi populist and to justify the killings (Das, 2006; Singh, 2009). Jarnail Singh (2009) states that members of the Congress Party of India, such as Jagdish Tytler, organized the riots. Survivors and witnesses discussed stories of how politicians led mobs, police helped the mobs, Sikh men were beaten and burnt alive, and women were raped (Singh, 2009). Furthermore, Das (2006) states that there is a dual aspect to the violence and that the local narrative is essential to consider. In many instances, perpetrators had some relation to the victim as an enraged Hindu narrative gave the opportunity to act out past issues (Das, 2006). Regardless, the trauma of the violence persists as the majority of the perpetrators never faced persecution (Das, 2006; Singh 2009).

\footnotetext{
${ }^{3}$ Other names used to describe this event include Sikh pogrom and Sikh genocide. Please be mindful of the name as it is a highly contested name internationally.
} 
Many Sikhs in the Diaspora felt insecure and fearful about their place in India after the events of 1984. This fear led to a demand for Khalistan (a separate homeland for the Sikhs) and an insurgency movement in Punjab (Dhillon 2007; Kaur 2009; Nijhawan \& Arora, 2013; Tatla, 1999,). Before Operation BlueStar, the demand for Khalistan was not as prevalent (Dhillon 2007; Kaur 2009; Jakobsh 2014; Tatla, 1999). Dhillon (2007) argues the demand for Khalistan has mostly subsided once stability had returned to Punjab. The insecurity caused by the events of 1984, the dangerous insurgency movements, and police responses to the insurgency movement created an influx of Sikhs looking for asylum in other countries as political refugees (Johnson, 2005; Judge, 2003; Tatla; 1999). This episode had turned Sikhs as economic migrants seeking better opportunities into political refugees seeking asylum.

The Canadian Sikh Diaspora and the Canadian South Asian Diaspora was impacted by the events of 1984, as those events indirectly led to the bombings of Air India in 1985. On June 23, 1985, Air India flight 182 was bombed out of the sky, killing hundreds of mostly Canadian citizens with Indian ancestry (Kasmeri and Mcandrew 2005; Jakobish, Nayar, 2004; 2014; Raqack, 2017; Seshia 2017). Babar Khalsa, which was led by Talwinder Singh Palmar, had organized the bomb in response to Operation Blue Star and Anti-Sikh riots. Canadian courts only ever convicted one person of the bombing (Jakobish, 2014; Kasmeri and Mcandrew 2005; Raqack, 2017; Seshia 2017). Canada is partially responsible for the bombings and the results of the court case, due to systemic racism in the pre-bombing assessment and post-bombing response (Jakobish; 2014; Rack, 2017; Razack, 2017). Canada ignored the warnings that Air India and the government of India gave, as threats coming from a nonwestern entity was viewed as an exaggeration. Canada did not take the appropriate steps to prevent the bombings (Raqack, 2017). Canada thought that Air India was an Indian tragedy and did not review the case seriously until 
after 9-11 had occurred (Raqack, 2017; Seshia 2017). However, Kasmeri and Mcandrew, (2005); and Sandhu (2018) contest the current narrative around the Air India bombing. They discuss the possibilities that the Indian Security Service (ISS) was involved in the Air India bombing and that the ISS goal was to tarnish the reputation of Sikhs in Canada (Kasmeri and Mcandrew, 2005; Sandhu, 2018). Kasmeri and Mcandrew (2005) argue that CSIS thought Talwinder Singh Palmar was an undercover Indian agent and the Air India bomb was meant to tarnish the Sikh communities' reputation in the diaspora. The ISS was spreading false rumors of Sikhs in Canada and ISS was falsely making accusations to Canadian government authorities about Sikhs (Kasmeri and Mcandrew 2005; Sandhu, 2018). Regardless of the guilty party in the Air India bombing, scholars argue this event negatively impacted Sikhs. The Sikh community bore the brunt of the accusations and was labeled a violent community for the actions of a few (Jakobish, 2014; Kasmeri and Mcandrew 2005; Nayar; 2004; Sandhu, 2018). The Air India bombing negatively impacted the Sikh community's reputation in Canada.

The last major event, the September $11^{\text {th }}$ attacks in the United States had devastating consequences for Sikhs globally, particularly in North America. The Sikh community faced an increase in discrimination post 9-11 (Ahluwalia \& Pellettiere 2010; Ahluwalia, 2013; Jakobsh \& Walton-Roberts, 2016; Mann, 2017; Paur, 2008; Sian, 2017). Views of Sikhs, especially those who wore turbans, included Al-Qaeda, anti-American, and terrorist (Ahluwalia \& Pellettiere 2010, Ahluwalia, 2013; Paur, 2008; Sian, 2017). Paur (2008) dictates that there was a 9-11 backlash with the first shooting happening in the United States to Balbir Singh Sodhi, a Sikh. Furthermore, Ahluwalia \& Pellettiere (2010) in their ethnographic study on Sikh men's experience in New York City found that Sikh men were being beaten up randomly due to the events of 9-11. They found that 83 percent of Sikhs encountered racism or knew someone who 
encountered racism and that Sikhs were facing institutional racism, such as finding a job (Ahluwalia \& Pellettiere, 2010, pp. 304 \& 309). Because of the hysteria and the fear that 9-11 caused, Sikhs faced instances of religious profiling by the state as Brown bodies and the turban is labeled as dangerous (Ahluwali, 2013; Mann, 2017; Paur, 2008). Specifically, in Canada, Mann (2017) and Sian (2017) discuss that Canadian Sikh's face issues of discrimination and profiling due to 9-11. These three episodes led to negative implications towards the Sikh diaspora, which are still prevalent today.

\section{Current Issues in The Canadian Sikh Diaspora}

Sikhs in Canada face problems because of their identity. Sikhs have a fear that they will face harassment, discrimination, and hate crimes (Jakobsh \& Walton-Roberts 2016), as many Sikhs do face issues of harassment and hate crimes due to their identity (Ahulwalia, 2013, Judge, 2003; Mann 2017). Racism towards the Sikh community occurs due to harmful identity constructions. Many Sikhs are confused as Muslims, and Muslims are confused as terrorists (Ahulwalia, 2013). This false labeling means that Sikhs are victims from targeted acts of violence towards their members and the community (Ahluwalia \& Pellettiere 2010; Ahluwalia, 2013; Paur, 2008). A notable contemporary example is of the Wisconsin Oak Creek Gurdwara shooting in which a White supremacist killed six Sikhs and injured others (Ahulwalia, 2013, Mann 2017). In Canada, the Sikh community has faced issues of hate crimes, such as vandalism towards gurdwaras (Jokobsh \& Walton-Roberts, 2016). Sikhs are more likely to face issues of violence in Canada than their non-Sikh counterparts because of harmful identity constructions.

Sikhs also face barriers towards practicing their faith. Sikhs have continuously fought against identity constructions the state has imposed on them, such as banning of kirpans or 
wearing a hard hat over a turban (Judge, 2003; Sandhu, 2018). Sandhu (2018) confers how in some regions of Canada, there are still issues with wearing a kirpan. An example is of Sikhs being barred entry into the Quebec legislator if they carry a kirpan (Jakobsh and Walton-Roberts, 2016). Kirpans are a required article of faith for devout Sikhs. Dhamoon (2013) contends contestations of a kirpan are rooted in hegemonic meanings of national identity. Thus, a lack of cultural competency places negative connotations towards Sikh's articles of faith. Identity politics have added restrictions towards a Sikh person's daily functions. Canada's policies prevent a Sikh from fully practicing their faith.

Government institutions profile Sikhs due to fears and insecurities. Sikhs are often profiled when they travel abroad, especially through airports (Deal, 2011; Sian, 2017; Mann 2017). Deal (2011) argues that in the name of airport security, checks at airports have become normalized and constitutional infringements are common. Sikhs, for example, lost their constitutional right to religion when they are given extra pat downs on their turbans and are forced to remove their turbans for airport security reasons (Deal, 2011). Additionally, Sian (2017) claims Sikhs have normalized receiving random searches and pat-downs at airports. Sikhs suspect to receive pat-downs. In some specific airports, Sikhs have complained about facing secondary screenings 100 percent of the time (Sian, 2017, 44). Sikhs also face issues when crossing the Canada-US border, as the borders determine which bodies belong and which bodies do not (Mann, 2017; Sian 2017). Specifically, in Canada, Mann (2017) contests Canada prioritized national security over civil liberties. Canada implemented policies that targeted "suspected immigrant groups (156)." Canada views Black and Brown bodies as a threat to Canada (Mann, 2017). Thus, Brown bodies face an increase of policing, interrogations, stop and search violations by the police force (Sian 2017, Mann 2017). 
Although the Sikh community is one that has faced discrimination, the Sikh population actively fights discrimination and is involved in social causes. The Sikh community has rallied around its community groups to fight for change. The Ghadar Party, for example, was created and organized by Punjabis, primarily Sikhs, of North America in response to the British occupation of India and the negative treatment of Indians in North America (Gill, 2014; Kaur 2009). The Ghadar party was active in fighting for India's independence and to recognize Sikhs as citizens, instead of the second-class treatment they got abroad (Gill; 2014; Kaur, 2009). Currently, Sikh organizations in the diaspora, such as United Sikhs, have been actively fighting against discrimination, fighting for civil rights and providing humanitarian aid (Kaur, 2009). Sikhs have successfully achieved some civil rights, such as wearing a turban in the RCMP or wearing a kirpan at Quebec public schools (Jokobsh \& Walton-Roberts, 2016). The work of Sikh groups and individual Sikhs has improved the Sikh image (Jokobsh \& Walton-Roberts, 2016). The positive work Sikh youth have done to promote the community attributes a large portion of this success (Jokobsh \& Walton-Roberts, 2016; Nijhawan \& Arora, 2013). Sikh youths have been active in leading social movements to reconstruct their identity positively (Jokobsh \& Walton-Roberts, 2016; Nijhawan \& Arora, 2013). The Sikh diaspora is politically active, fighting to bring forth positive change.

\section{Racial Profiling And Bias: The Overrepresentation of Minorities}

Racial disparities are prevalent in the criminal justice system. A person's skin color impacts a person's experience during a pullover. Black and Aboriginal individuals are much more likely to face random stops in comparison to White individuals (Epp, Marnard-Moody and Haider-Markel, 2014; Wortley, 2003; Close and Mckeena, 2006; Tator and Henery, 2006; Comack, 2012). Epp, Marnard-Moody, and Haider-Markel (2014) investigated the reason why 
the Black population faced double the number of traffic stops in the United States, in comparison to the White majority. The Black community was stopped at a similar rate as the White community for traffic violations, as the police's objective, in this case, was to halt extreme offenders. However, the Black community was stopped at a much higher level for a low traffic violation or no reason than the White community, as the police's objective, in this case, was to investigate those whom they thought were suspicious individuals (Epp, Marnard-Moody \& Haider-Markel, 2014). Supportively, Wortley (2003) discusses how Black males, especially older rich Black men are the most likely to face random police stops and searches compared to any other group in Toronto. One of Wortley's respondent discussed that a Black person driving a nice car is stereotyped as being a drug dealer or stealing the car (Wortley, 2003, 104). Also, Close and Mckenna (2006) discuss how the Black population in Kingston, Ontario are three times more likely to be stopped and questioned by the police than any other group (Close and Mckeena, 2006). Because of systemic bias, the Black and Aboriginal population face a higher proportion of police stops.

Racial bias is also evident in police investigative practices. Police investigative practices target the Black and Aboriginal communities (Comack, 2012; Marnard-Moody \& HaiderMarkel, 2014; Morton, 205; Smith and Tator and Henry, 2006; Smith and Alpert; 2007; Wortley, 2003). Wortley's (2003) describes how $65 \%$ of Black high school drug dealers reported officers arresting them at least once in their lifetime while $35 \%$ of White high school drug dealers reported officers arresting them at least once in their lifetime (104). This disparity occurs because the police monitored Black high school students at a much higher rate (Wortley, 2003). Racial minorities are often profiled by the police, in which the police investigate an individual on the assumption that they will conduct or are conducting criminal activity, instead of knowing that 
they did commit an illegal activity (Tator and Henry, 2006). Thus, Black Canadians represent a disproportionate number of searches (Owusu-Bempah and Wortley2014; Hier and Walby, 2006). The investigative practice of carding is an example of police disproportionately targeting minority groups (Morton, 2015; Meng, 2017). Racial minorities are more likely to face police investigative practices than other groups.

Minorities are also more likely to face severe police interactions. Tator and Henry (2006) explain how Black Canadians face instances of racial slurs, searches, and violence in some interactions with police officers. Violent situations include stories of severe assaults, although no crime was committed (Tator and Henery, 2006). Furthermore, Black Canadians and Aboriginals represent a disproportionate amount of deaths due to excessive police force (Wortley, 2003; Comack, 2012). According to Wortley's (2003) analysis of newspaper reports, Black Canadians made up 56\% of police-related deaths from 1978 to 2000 (10), though Black Canadians made up four percent of Ontario's population. Minorities are also more likely to face abusive police practices, such as the practice of starlight tours towards Aboriginals. This practice involves a police officer forcing an Aboriginal person into the back of a police cruiser, driving them a few kilometers off city limits and leaving them there, often taking their shoes and jackets (Comack, 2012). The Aboriginal person would have to find their way back to the city (Comack, 2012). This practice has led to the deaths of civilians. The review of the literature indicates that a person's skin color impacts the severity of the police interaction.

Racial minorities face biases in all other aspects of the criminal justice system. Black and Aboriginals are treated more negatively in courts (Tator and Henry, 2006). According to Tator and Henry, (2006), one-third of judges, as well as almost forty percent of defense lawyers felt that Black Canadians were treated differently in courts. Statistically, Black individuals were 
more likely to be prosecuted for drug offences, more likely to be denied bail, and more likely to be arrested and sent to jail for smaller crimes (Owusu-Bempah and Wortley, 2014; Roberts and Doob, 1997). Black individuals are also more likely to violate bail terms as authorities give them stricter conditions (Roberts and Doob, 1997; Wortley, 2003). In jails, Canada has a disproportionately high incarceration rate for Aboriginals and Black Canadians (Owusu-Bempah and Wortley, 2014; Roberts and Doob, 1997). Furthermore, Roberts and Doob (1997) argue racial minorities face harsher treatment in jails as racist attitudes plague prisons. Because of racial bias, Black and Aboriginal groups face negative treatment in all aspects of the criminal justice system.

Racial groups have different assessments of the police due to their experiences with law enforcement. Wortley and Owusu-Bempah (2009) conducted a study on how Black, Asian, White, and immigrant population viewed the police and the Canadian criminal justice system. Overall, minorities view the criminal justice system less favorably than White Canadians (O'Conner, 2008; Wortley and Owusu-Bempah, 2009). Minorities have less favorable views because minorities are more likely to face discrimination by the police, negative treatment by the police and feel as police abuse their authority. The Black population especially believes that they are targeted by policing (Wortley and Owusu-Bempah, 2009). In contrast, Atiba, Goff and Kahn (2012); Hier and Walby (2006) argue other racial groups also think the police discriminate against the Black population. Public opinion impacts the effectiveness of policing, as information the public shares are valuable for the police (O'Conner, 2008). An individual is less likely to rely on the police during an emergency when the individual has negative sentiments of the police force (Anderson, 1999). These studies demonstrate how minorities perception of the police has been impacted negatively, which in turn affects the quality of police service to the community. 


\section{Theories of Racial Bias}

There are a variety of factors that lead to racial bias. Variety of scholars suggest racialization causes racial prejudice. Racialization is attaching characteristics to an ethnic group (Comack, 2012; Murji and Solomon, 2004). According to Comack (2012), racialization creates differences as different racial categories and identities are constructed (17). These socially constructed views are normalized and impact an individual's view of a person from another ethnic group (Comack, 2012). This process is damaging when socially constructed negative meanings are attached to a racial category (Comack, 2012). Chan and Chunn (2014) discuss how racialized views lead to minority migrants being viewed as threatening and violent to national sovereignty (Tator and Henry, 2006). Racialization creates a culture of fear and control, which leads to racial politics that subjugate minorities (Tator and Henry, 2006). This process of racialization creates a racial hierarchy of cultures and leads to acts of racism.

The process of racialization is especially damaging when police officers attach racialized views to different groups, a term known as racialized policing. Police officers are not immune to racialization. Police officers are a representation of the community's belief and racialized beliefs are passed down to them from different groups such as parents and social leaders (Smith and Alpert, 2007). Racialized views will impact the treatment minority groups receive from police officers, as racialized views interpret racial traits as a trait of crime (Chann and Chunn, 2014). Smith and Alpert (2007) contend a police officer's racialized views subconsciously creates racial profiling. These racialized views lead to the overrepresentation of minorities in different statistics, such as the overrepresentation of Aboriginals in police shootings (Comack, 2012). The process of racialization impacts daily interactions towards racial minorities. 
Racialization creates and reproduces stereotypical views towards different demographics. Ingrained stereotypes impact a person's actions, perceptions, and attitudes towards different groups (Carroll and Gonzalez, 2014; Comack, 2012; Gorbunova et al., 2015; Johnson, 2007; Smith and Alpert, 2007). Gorbunova and others (2015) discuss how in their experiment of Berlin neighborhoods, participants gave less trust towards those who resided in negatively stereotyped neighborhoods than those who lived in a positive stereotyped neighborhoods (Gorbunova et al, 2015). Lower income and unfavorable sociodemographic live in negatively stereotyped neighborhoods. Participants view negative stereotyped neighborhoods as less safe compared to other neighborhoods (Gorbunova et al, 2015). Stereotypes impact police practices (Johnson, 2007; Carroll and Gonzalez, 2014). Johnson (2007) conducted a study in which he analyzed the behaviors of guilty and non-guilty Black and White civilians when they were interacting with police officers. Johnson (2007) argues that police are taught to look for specific cues, such as constant hand gestures, pauses in speech and smiles, to determine who is lying and who is likely to be a criminal. Innocent Black civilians were more likely to display characteristics officers were taught to look for than any other groups that were studied (Johnsn, 2007). Thus Black civilian characteristics are stereotyped as belonging to a criminal. Furthermore, Carroll and Gonzalez (2014) discuss how stereotypes impact a police officer's quick judgement. An officer is more likely to frisk a Black person during a pullover, as an officer is quickly assessing who is dangerous and who is not. This bias was less prevalent in a search, as the officer had more time to evaluate the scenario (Gonzolaez, 2014). Officers stereotype more when they have less time to determine who is dangerous (Gonzolez, 2014). Because of ingrained stereotypes, minority groups face harsher treatment. 
In addition to racialization, critical white theorists argue racial profiling occurs because a White person's traits are considered normal, while nonwhites traits are considered abnormal (Tator and Henry, 2006; Nayak, 2005; Nayak 2007). These scholars argue not enough attention is given to the role White groups have in the construction of minority groups. Nayak (2005) theorizes how whiteness escapes racialization, thus becomes normative and dominate. All other groups racialization is tied to whiteness and thus compares racial traits to normative "white" traits (Nayak, 2005; Nayak, 2007). The White man's fantasy constructs the view of minorities such as depicting Black people as macho, savage and Brown people as feminine and weak (Nayak, 2007). This theory is most evident in crime. Tator and Henry (2006) discuss how a racial minority group receives blame for offenses committed by a few of its members. In contrast, the whole White community does not receive blame for crimes committed by a few of its members. Instead, the community will label the offense as a regular part of the society (Tator and Henry, 2006). Whiteness creates a double standard and impacts the perception of ethnic minorities.

In addition to police bias, the law is a source of racial bias which impacts police relations with minorities. Critical race theorists argue law has historically subjugated racialized minorities (Alyward. 1999, Glover, 2009). Glover (2009) explains that historically, the United States policies have embedded racism, such as the constitution. The United States drafted those policies for the White elite. In Canada, Aylward (1999) discusses how policies were used to exclude racial minorities and allowed for slavery. Both Alyward (1999) and Glover (2009) argue the state did not make racial progress. Instead, racism is still present when one critically examines law and law enforcement (Alyward, 1999; Glover, 2009). Past formal racial practices impact current informal practices (Glover, 2009). Also, Bell (1995) argues a Black person's rights have been 
decreasing, not increasing. Bell (1995) claims laws cannot be written from a neutral perspective as everyone speaks from his or her point of view. Racial minorities points of views have been historically oppressed and ignored (Bell, 1995, 901). In Canada, a ban on collecting race-based data has been detrimental in proving whether racial bias exists, which makes it harder to make recommendations on how to counteract racial profiling (Closs and Mckenna, 2006; Wortley, 2003). The neutral approach denies the existence of racism, prevents policies that make for racial progress, and provides for the continuation of racial discrimination (Bell, 1995). Laws have been constructed to oppress ethnic groups.

Lastly, racialization, white privilege, and racially biased laws are reinforced continuously by negative depictions of racial minorities in the media. Potter and Kappeler (2012) discuss how media blurs fiction from reality and creates fears, prejudices, stereotypes and pervasive impulses. Crime coverage focuses on violent crimes, especially crimes committed by ethnic minorities. Crime coverage also focuses on victims as being children and women (Potter and Kappeler, 2012). The media constructs the image of minorities to the White populace (Henry and Tator, 2006). The media racializes minority groups as violent and as criminals to the masses (Potter and Kappeler, 2012). Supportively, Roberts and Stalans (1997); Tator and Henry (2006) discuss how the majority of the populace rely on the media for their judgments and opinions on crime. Public opinion plays a significant role in criminal law. The public tends to believe delinquency is rampant and that not enough is done to prevent crime (Tator and Henry, 2006; Roberts and Stalans, 1997). The fear of crime and the overrepresentation of minority violent crimes in the media justifies strict police practices towards minority groups. 


\section{Conclusion: The Racial Profiling Practice of Carding and The Sikh Diaspora}

This literature review has depicted how colonialism, Komagata Maru, Operation Blue Star, Anti-Sikh Riots, the Air India bombing, and 9-11 negatively impacted the Canadian Sikh diaspora. As the research has shown, Sikhs currently face issues of discrimination and oppression. This review of the literature has stated that the Black and Aboriginal populations are overrepresented in many crime statistics because they face racial biases from the police force. As the review of the literature has noted, the Sikh community faces instances of profiling in different institutions. However, there is an apparent lack of literature when discussing a Sikh person's profiling issues towards policing. Discussion of the Sikh experience to profiling when traveling abroad, such as at airports, is evident in the scholarly literature. Literature towards a Black and Aboriginal experience in racial profiling by policing is considerable. Discussions towards racial profiling by the police to the Sikh community is limited. Carding is a controversial police practice in Canada as it is a form of racial profiling. Scholarly articles have discussed how carding impacts Black Canadians. No academic article explains a Sikh person's experience towards racial profiling. Thus, there is a literature gap towards racial profiling towards the Sikh community. This dissertation addresses this literature gap. 


\section{Chapter 2: Methodology}

The goal of this thesis project is to understand the Sikh male's perception of carding. Moreover, this thesis analyzes how carding impacted Sikh men, such as their views towards police officers. The main research question that this thesis examines is "how Canadian Sikh males in Ontario are affected by random police stops?" This thesis project has conducted an ethnographic study, with a focus on narratives to answer these sets of inquiries. To locate the participants, I used methods that directly engaged with the participants. I used the research method called memoing throughout the study to obtain a preliminary understanding of the data. Finally, the directed content analysis approach was used to analyze the data. There are many challenges and obstacles towards this thesis project. The research design below is the best way to meet those challenges.

\section{Method of Research: The Benefits of Ethnography}

This thesis took a qualitative approach to understand the Sikh male's view of carding over a quantitative approach. A qualitative approach searches for the participants' subjective perception (Heyink and Tymstra, 1993). In a qualitative study, the researcher is directly involved in the field of study. The researcher is the primary instrument for data collection (Merrian, 2009). The sample size is also smaller than a quantitative study as the researcher gives more attention to participants then a quantitative study. More attention is beneficial as a qualitative approach searches for why things exist, how people make sense of their lives, and interprets the participants' experiences (Heyink and Tymstra, 1993; Merrian, 2009). Thus, a qualitative study produces in-depth knowledge that is currently missing from the Sikh perspective to carding (Flyybjerg, 2006). However, the downfall of this approach is that it cannot describe facts, such as what percentage of Sikhs get carded, as this method targets a small sample size. 
This dissertation conducted an ethnography for the purpose and goals of this research project. Unlike other research methods, ethnographies directly obtain data from those who are the object of study (Flood, 2005). This method gives a closeness to the research subjects that would not have occurred with other research methods (Mcneil and Chapman, 2005). Ethnographies give insight into the richness of social life and individuals opinions, values and beliefs (Flood; 2005; Mcneil and Chapman, 2005; Shagir, 2017). The insights are significant, as ethnographies provide understandings into the actual reality and a person's perception, as expressed by the surrounding and actions around them. For this reason, ethnographies produce more in-depth knowledge than any other type of qualitative and quantitative research method (Flood, 2005). Ethnographies permitted this project to understand the Sikh perspective towards being street checked. However, the downfall of this method is that it interviews a small sample size to understand the depth of the problem, not breadth. Therefore, ethnographies cannot account for the viewpoint of the entire Sikh community.

This ethnographic research design utilized semi-structured interviews. Semi-structured interviews give the interviewee more flexibility than a structured interview. Semi-structured interviews also ensure that the researcher stays on task to the objectives of the research project in contrast to an unstructured approach (Brinkanan, 2013; Gubrium and Holstein, 2001). Semistructured interviews elicit information or expression of belief from another person. In interviews, we learn the respondents' worldviews (Brinkanan, 2013). Respondents provide the researcher detailed descriptions of their thoughts, feelings, and activities (Gubrium and Holstein 2001). The conversations from the interviews provide a rich and indispensable source of knowledge about personal and social aspects (Brinkanan, 2013). This method allows the researcher to delve deeply into social and personal matters (Bloom and Crabtree, 2006). Thus, 
semi-structured interviews allow for an understanding of complex social issues, such as carding towards the Sikh community.

A portion of the interview instrument was based off a narrative analysis approach known as narrative interviewing. Narrative interview can be used in conjunction with semistructured or structured interviews (Anderson and Kirkpatrick, 2006). This dissertation utilized narrative interview when probing for stories in the participants carding incident and sometimes when probing for the participants' racial experience. Narrative interview gives the participant the opportunity to tell their story, instead of just answering questions (Allen, 2017). Participants were asked open-ended questions to encourage storytelling. Narratives are useful as the participant's story provides meaning to their event (Allen, 2017; Anderson and Kirkpatrick, 2006). Narrative's give an understanding of how individuals construct their experience (Allen, 2017). Narratives also bridge social interactions with large-scale social structures as the participants reveal how they been affected by power relations (Ewick \& Silbey, 1995). Thus, the participants' narratives dictate how power relation exerted by the police and policy-making institutions impacted them (Ewick \& Silbey, 1995). Narrative interviews are also important in this project as storytelling is a preferred teaching method and a popular discourse method in the Sikh community. Storytelling has been used to share Sikh history and values from the older generation to the younger generation, from my experience of being a Sikh.

\section{$\underline{\text { Recruitment and Participant Pool }}$}

This thesis project used recruitment methods that directly engage the participant to the researcher, such as utilizing interpersonal connections, handing out flyers, and word of mouth advertising. These methods were successful as they built rapport before the interviews began. Rapport is required to gain access to the research participants in this project, due to the 
sensitivity of the research topic and the fear of being associated with their carding experience. A participant can have a difficult time talking about their carding experience. The researcher needs to have the participants trust so that a participant will be open about their experiences and to access rich research material (Kennedy-Macfoy, 2013). Ensuring the person conducting interviews is a part of the community is one way to build rapport, as I was in this study. Another way is to be able to identify with the participants. Being able to identify with the participant through similarities such as religion, race, and association means that that the researcher will be more successful in conducting interviews and gaining access to rich research material (Turgo, 2012). In this study, the participants built an association with the researcher before the interview commenced or heard about the researcher from mutual contacts. The participants would realize that the researcher, just like the participant, was of Sikh descent. The participants would also have learned that the researcher faced similar experiences and had the cultural sensitivity to be interviewing them. Rapport will make the participants more comfortable to partake in this project (McLean and Campbell, 2010). As a young Brown Sikh male who has been randomly street checked, I can relate to another Sikh male's experience and thus will be culturally sensitive during the interview.

Rapport is especially important when conducting an ethnography towards a South Asian community. Mclean and Campbell (2010) study analyzed the effectiveness of different recruitment methods for different ethnicities. When commencing a research project towards a South Asian community, an honorarium is not a motivating nor an essential factor for a participant (Mclean and Campbell, 2010). In this thesis project, many of the participants initially refused to accept an honorarium. Instead, trust was the most crucial factor for a participant to want to partake in this study. Mclean and Campbell (2010) found that personal contacts, 
introduction through mutual connections, and face to face interactions were the most successful recruiting methods for recruiting South Asian research participants. In this project, almost all the participants built an association with the researcher before the interview had commenced. The participants liked the topic that was being explored but only participated because they had trusted me in conducting the interview. For any future researcher who plans to replicate this thesis design, building a relationship with the participant is crucial during the recruitment stage. A downfall of this method is that age will impact whom a researcher can recruit (Mclean and Campbell, 2010). As a young person, it was easier for me to recruit other young Sikh males, than to recruit older Sikh males, as I was more relatable to a young Sikh male. Thus, an older Sikh man will have difficulty recruiting a younger Sikh male than an older Sikh male.

Other notable recruitment methods include advertising by posters in areas with a large concentration of Punjabi Sikhs such as local Gurdwaras (Sikh places of worship) and local ethnic community businesses such as Indian grocery stores. This project used social media platforms such as Facebook sponsored posts, and relevant community Facebook pages. I made posts on a variety of community websites such as the South Asian Legal Clinic website and SikhNet. This project obtained permission to advertise on media platforms and local organizations. As this project is partnered with United Sikhs - a UN-affiliated not for profit organization that provides humanitarian relief and fights for minority rights - posts were made on their social media pages and emails were circulated from their Ontario email database. I also spoke about the project on Punjabi radio stations. These methods did provide a few responses and a few research participants, but they were not an effective method of recruiting because they did not build rapport compared to methods that directly engaged with the participants. 
This thesis project obtained research participants from the province of Ontario, specifically from the western part of the Greater Toronto Area (GTA). The GTA, specifically the Peel Region, has one of the largest concentrations of Sikhs outside of India. Because of limited funding, time, connections, and access to a vehicle, almost all the interviews occurred in the Western part of the GTA as it was the most realistically possible. Permission from local community hubs, such as Gurdwaras, and Indian grocery stores was obtained to conduct recruitment. Due to the sensitivity and the specifics of this topic, a variety of recruitment methods were used from August 2017 to November 2017 to collect a sufficient sample size for this ethnographic study. In total, this study recruited sixteen participants. These many participants led to partial saturation.

\section{Procedure in The Interview}

Once I recruited the participant, the participant and I discussed a time and a safe space that was convenient for both of us. Once the participant and I had met, I went over the details and the goals of the project to the participant. I gave the participant a consent form, and we discussed the participant's rights in this study. During this time, the participant was given a tendollar Tim Horton's gift card as an honorarium for their time. The interviews commenced when the participant gave their consent and continued for as long as participant gave ongoing consent. The estimated one-hour semi-structured interview had begun. On average, the interviews lasted for fifty minutes, ranging from twenty minutes to an hour and a half. As this was a semistructured interview, some of the questions were prepared before the meeting, while other inquiries arose from the responses the participants gave. I transcribed all the interviews, and I 
coded the data into the software called NVivo. After the coding stage, this project analyzed the data.

$\underline{\text { Interview Instrument }}$

A few of the questions in the interview instrument gauged for specific responses, such as the respondent's age. Some of the queries were open-ended, to encourage storytelling. For example, one of the research questions asked the participants, "What happened when you were pulled over?" I prepared many questions in case a participant was reserved to probe for responses that will answer the research questions. In most interviews, I only used a portion of the interview instrument.

This project utilized four different sets of questions during the interview period. Theoretical frameworks and local knowledge influenced this project's first set of questions for the interview instrument. The preceding set of questions shifted based on discoveries and patterns.

I divided the interview instrument into four categories. The four categories are, Introduction, Being Questioned by The Police Officer, Perceptions of The Event and The Police, and Is Change Required. The introduction portion categorized the participants into their respective categories, such as their age, and location. This section gave some background information about the participants to understand what variables might impact the participant's responses. "Being Questioned by The Police Officer" section describes the participants carding incident(s). "Perception of The Event and The Police" describes how carding impacted the participant and how their perceptions had changed. The final section, "Is Change Required," is a 
short follow up section, inquiring on the participants' perception of what needs to occur with carding.

\section{Pre-Data Analysis: Memoing}

This thesis project utilized memoing to gain a preliminary understanding of the data. Memoing was used during the fieldwork stage, the transcription stage and the initial analysis stage. Memoing is the process of recording reflexive notes on what the researcher was learning (Groenwald, 2012). We humans continuously forget our old ideas as new ideas emerge (Emerson, Fretz, and Shaw, 2011). Jotting down reflexive notes means that old ideas will stay on paper permanently. During the fieldwork stage, memoing gives insight, direction, and guidance (Emerson, Fretz, and Shaw, 2011). For this project, memoing gave direction towards patterns this project should focus on during interviews and helped to develop better versions of the research instrument. During the coding stage, preliminary patterns produced by memoing aided the development of a preliminary coding strategy. Memoing is especially helpful during the analysis stage. The initial patterns produced from memoing helped to identify and explore a general pattern (Emerson, Fretz, and Shaw 2011; Birks, Chapman, and Francis, 2008). Overall, because this type of project produces large amounts of data, memoing permitted for flexible retention of data and keeps the researcher focused on finding a general pattern.

\section{Data Analysis: Directed Content Analysis Approach}

This thesis project used a directed content analysis approach to analyze the data, as this thesis project will be adding to prior research instead of creating a new theory. According to Hsieh and Shannon, "The goal of a directed approach to content analysis is to validate or extend 
conceptually a theoretical framework or theory (Hsieh \& Shannon, 2005, 1281)." No exact theory will explain how carding affects the Sikh population, as there has never been a study on how carding has affected the Sikh community. However, this thesis project was guided by the racialization theoretical framework, as it applies to this thesis project. Directed content analysis approach is beneficial as it allows for a structured analysis of data (Hsieh, \& Shannon, 2005). Directed content analysis emphasizes creating a coding strategy by identifying key concepts or variables from past research (Hsieh, \& Shannon, 2005). Initial coding creates a structured view that provides an efficient and robust analytical framework, which is missing from other analytical frameworks. This dissertation divided the initial coding structure into different categories, based on current literature towards racial profiling. These were useful in first organizing data and obtaining a preliminary understanding of the data. Afterwards, discoveries changed the coding structure. As this project made more discoveries and found more patterns, this project added more codes. At the end of the analysis, the coding structure and the additional codes were merged into a few major categories to discover major themes that would answer the research questions. Therefore, the directed content analysis approach provides better results than other types of analysis methods, such as grounded theory, extended case method, and conventional content analysis. Directed content analysis effectively and efficiently analyzes data and either supports or extends an existing theoretical framework.

\section{Ethics: The Importance of Privacy and Confidentiality}

Due to the sensitivity of this topic and the fact that this project interviewed participants, measures were taken to safeguard the privacy concerns of the participants. There are many ethical concerns about this thesis project as this topic can be difficult for some participants to 
discuss. There was a general fear by some of the participants that their future ambitions, such as a career in policing, will be impacted if their information was released. Participants were also worried about receiving backlash from community members they knew such as their parents. Due care was taken to protect the identity of the participants. Pseudonyms were assigned to hide the participants' identities. Pseudonym includes full cultural names such as Gurjeet, Sukdeep, and Harbhajan, or they included cultural nicknames such as Randy or Paul.

During the interviews, the participants and I conducted interviews in places that the participants were comfortable conducting it in as well as in locations that kept the participants' information private. This project conducted interviews in places that were private or semi-private to ensure the privacy and confidentiality of the participants. Examples include private rooms, cars, houses, and private areas of coffee shops. These different options met the different confidential, privacy, and accessibility requirements the participants had. Before the interviews commenced, I gave the participants a consent form, which outlined the rights they had as a participant. I informed the participants that they could refuse to answer any question they did not want to answer. The participants could terminate the study at any time they like. The consent form also provided participants with contact information to a free Sikh Family Helpline if the experiences were very troubling. The Sikh Family Helpline number is 1-800-551-9128. I will also provide contact with counseling services if needed. The counseling services is called the Punjabi Community Health Service, a social service organization located in a few cities across Canada. Interviews only commenced once consent was given to conduct interviews and when consent was given to audio record the data. In a few instances, consent was not given to audio record the data. Thus I took field notes of the interview instead. The interview would only commence for as long as ongoing consent was given to conduct the interview. I had continuously 
asked if it was okay to continue the interviews to maintain ongoing consent. As a person who is embedded in the Sikh community and has the cultural sensitivity towards the Sikh community, I made sure to ask questions that were respectful to the participant and their experiences.

All audio recordings and transcriptions were kept safe under a pass-coded computer to ensure the privacy and confidentiality of the participants. All audio recordings were destroyed once they had been transcribed. All transcripts were encrypted with different codes. All the codes were kept safe in a codebook under lock and key. The participants had the option to terminate their data if they chose to do so before I started to analyze the data. The research ethics board approved this project on July 17, 2017.

\section{Limitations}

There are a few notable limitations in this research design. Due to the time, resources, and sensitivity of the research topic, this project is limited to the number of participants it could reasonably recruit. As young males get carded more than older males, it was more challenging to recruit older Sikh males for this thesis project. Also, as I am a young Sikh male, it was easier to build rapport with a younger Sikh male than it was for an older Sikh male. Thus, there was a more substantial youth presence in this project. This project does not account for the unique experiences of the whole Sikh community as the project collected a small sample size. Instead, this project gives a general understanding of the Sikh experience to carding. 


\section{Chapter 3: Racialization: The Sikh Experience In Canada}

Sikhism is the world's fifth largest religion, consisting of 27 million people. Majority of the Sikh population lives in India, specifically the northern state of Punjab. According to World Atlas, a website devoted to demographics and world geography, nine out of ten Sikhs live in India (Pariona, 2017). The largest diaspora outside of India is in Canada, with about 650,000 followers, 220000 more than the next country, the United Kingdom (Pariona, 2017). The Canadian Sikh diaspora had an exponential growth from what the population was a decade earlier. According to Johnson (2005), in 2001, Canada had 278,415 Sikh followers. The United Kingdom had a larger Sikh diaspora population than Canada (Johnson, 2005). Large numbers of Sikhs have immigrated in the recent two decades. Out of all the Sikh diasporas, Canada's Sikh diaspora was the most rapidly growing (Johnson, 2005). To Sikhs, Canada is viewed favorably because of its transparency, open immigration policies compared to other countries, and a strong, settled Sikh Diaspora.

\section{$\underline{\text { View of Canada }}$}

Overall, the participants had favorable views of Canada. Those who immigrated or grew up in another country were generally happy with their life in Canada. An example is of Avneet Grewal. Avneet was twenty-four at the time of the interview. Although he was born in Canada, a significant part of Avneet's childhood was spent in a boarding school in India. When asked about his overall experience in Canada, Avneet said:

Would say it is [a] satisfying experience. Like it's the greatest country in the world, to be honest, it's a great country to live in. The most friendliest people on the earth, and compared to India, where I have lived, you can tell why Canada is the greatest 
country in the world. Like people are more friendly here, the roads are not littered by cows or garbage. People are genuinely polite, you know, they are understanding and also the education is better here. Over there it is more procrastination based while here it is more critical thinking base. It really helps to develop a person you know. He thinks for himself rather on what he is taught you know. umm so yea, Canada is the best I would say.

Avneet prefers Canada over India because of its environment, culture, people, and education. Avneet has strong nationalistic sentiments, which is also reflected by some of the participants.

Other participants had a less positive view of Canada in comparison to Avneet. Overall, they too prefer the country and are happy that they immigrated or grew up in Canada. An example is of Gurdial Singh, from Punjab, India. Gurdial Singh was sixty-one at the time of the interview. He first came visited in December of 2000. Gurdial lived in different parts of the Peel Region. Like many Sikh immigrants, Gurdial worked vigorously to settle with his family, beginning as a factory worker to eventually become a business owner. He immigrated because he views Canada as a land of opportunities and as a place where his kids could become successful. However, Gurdial was doing well in India, and he did face hardships in Canada. When asked if overall, he is happy that he immigrated, Gurdial said, "There are both experiences. I have negative experiences; I have positive experiences. Like overall I will say I am happy.” Overall Gurdial has enjoyed his experience. His response, however, does indicate that there are issues with the Canadian Sikh experience. 


\section{$\underline{\text { Hardships }}$}

Generally, the participants faced hardships due to their identity. According to Johnston (2014), historically, Canadians were against Sikhs immigration. Past Prime Minister, Sir Wilford Laurier stereotyped that the Hindus (all South Asians were generalized as Hindus during Sir Wilford Laurier's era) would not survive in Canada's climate. Laurier justified the banning of Sikhs (Nachiappan, 2017). Another past Prime Minister, William Lyon Mackenzie King outright declared that Sikhs should not live in Canada (Nachiappan, 2017). The Canadian Government created laws to prevent Sikh and other racial minority immigration. An example is of the continuous journey regulation. The continuous journey regulation was an act that required all immigrants to land in Canada by continuous journey from the immigrant's origin country (Johnson, 2014). This act made it difficult for South Asian immigration. During this period, the Canadian government offered free land to Europeans to increase the population of the prairies. I have personally heard stories of discrimination that community members faced during the 1980 s. Some Canadians verbally assaulted South Asians with racial slurs, such as by the word Paki. Paki is a derogatory term used against anyone of South Asian descent. I have also heard stories of physical assaults. My uncle faced a physical assault. He would carry a cricket bat with him when he drove his taxi, for safety. Stories of discrimination during this era are prevalent.

Today, some portions of the Canadian population have negative views of Sikh immigration. Media reports indicate that currently there are anti-Sikh sentiments in Canada. A very recent trending example is of Jaswinder Singh, who was told by a legion in Prince Edward Island to remove his turban. When Jaswinder refused, he was told by members of the legion to go back to his country (Bruce, 2018). In Brampton, a very ethnically diverse city with a large South Asian population, flyers were circulated in certain neighborhoods with a picture of Sikhs 
protesting, depicting "is this what you really want (Corbeil, 2014)?" The message of the flyer was that Sikh immigration is bad for the country. A newspaper article called How Brampton, a town in suburban Ontario, was dubbed a ghetto, argues that Brampton was named a 'ghetto' because of its large South Asian (mainly Sikh) population (Ahmed-Ullah, 2017). Similarly, racist posters were put up at the University of Alberta campus, which depicted things like "fuck your turban," and "if you're so obsessed with your third-world culture, go the fuck back to where you came from (Theobald, 2016)!"

These contemporary examples illustrate how the Sikh community still faces hardships in Canada, due to their identity. Numerous participants in this study have either faced, seen, or heard stories of discrimination. The common types of discrimination faced were discrimination due to being an immigrant, outright discrimination, and institutional discrimination.

Immigration, Discrimination, Youths, and Bullying

A surprising form of discrimination was participants facing discrimination by fellow community members. This type of discrimination in this study mainly happened to those who immigrated from India and were attending high school. Randy was a participant who faced this sort of discrimination. Randy immigrated to Canada when he was in grade eight. Randy kept a turban at that time. Randy felt that he was targeted because of his turban when he was attending high school. According to Randy, "Grade nine was the time when in high school, everyone were saying a lot of stuff about turbans." When discussing who was committing the bullying, Randy said:

Its usually people of our own race that are born here, that is what surprises me. There are a lot of people that, a lot of young guys that are born here, they don't have hair 
because they cut it when they were, when they were young. And now they make a joke here and there.”

The high school Randy attended had a large percentage of people who were of the Sikh community and were born and raised in Canada. Members of his community bullied him because Randy had a different appearance and was from India. Born and raised Sikh Canadians negatively racialize Sikh immigrants. From my experience as a Sikh born and raised in Canada, many born and raised Sikh Canadians make various derogatory conversations towards first generation Sikhs. Second generation Sikhs often discuss these conversations when an immigrant Sikh is not present. Common racialized views towards immigrants that I have encountered are violent, lazy, dirty, spoiled, creepy, and wasting Canadian resources. Prevalent derogatory words used to describe immigrants are $\operatorname{Ref}$, which is a derogatory term claiming them to be a refugee and that refugees are bad or $F O B$, which is short for Fresh Off The Boat. These racialized views will impact a person's judgement towards immigrant students (Comack, 2012). An immigrant Sikh child is likely to face bullying by a second generation Sikh because of these racialized views.

Randy also faced bullying from White students due to his appearance and personality. Immigrant Sikh youths' bullying experience negatively impacts them. Randy discussed impacts he and Sikh youths face because of bullying. While discussing turbans and bullying, Randy said:

That's why people tried to go away from that side and cut the turban or cut the hair. Cause everyone makes comments, everyone says something about it, in a funny way. [...] When [in a distraught voice] you are young as a kid, you think, why are people laughing at me. I used to cry in hallways of my high school. Cause, people will talk to me in class, ok because I was smart. I was really smart, I had a 93 average. And, as 
soon as I would get out of class, no one would talk to me, lunch period, no one would approach me, cause I wasn't cool enough to be around. I was only a nerdy kid, with the turban. You get what I am saying. So, so that eventually makes you feel alone, although you came from a different country and you feel lonely because nobody wants to talk to you."

Randy was emotionally impacted by bullying. Randy felt ostracized and would cry because of his experiences. Randy argues Sikh youths cut their hair to avoid bullying and ostracization. According to scholar Rita Verma (2006), many young Sikh males faced dilemmas about cutting their hair so that they would fit in with the rest of society, especially after the events of $9 / 11$ (Verma, 2006). ${ }^{4}$ Verma found that bullying had psychologically impacted Sikh students. These students' grades faltered, they started to skip school, and had more cases of depression (Verma, 2006). However, a Sikh is also psychologically impacted when they cut their hair and their turban. A Sikh person's hair is symbolic, and their turbans identify them. To some of us Sikhs, cutting our turban and our hair means losing our identity and a sense of our self. Thus, Sikh youths can face a dilemma because of their identity.

\section{Outright Discrimination}

Some participants witnessed or received verbal and/or physical assault. Some of the participant's assault scenario had turned into a fight. Hardeek and Sukhdeep are both nonobservant members of the community who witnessed racialized attacks. They were interviewed together as they were carded together in one of their carding scenarios. Sukhdeep was born and raised in Canada. Hardeek was born and raised in the United States of America, moving to

\footnotetext{
${ }^{4}$ A short film, called Balbir The Barbar shows the delima of a Sikh youth who is debating cutting his hair. If you would like to know more, click on this link https://www.youtube.com/watch?v=1MU89WMkN-0 or search up the film Balbir the Barbar on youtube and begin the film at 5:40.
} 
Canada during his high school years. When asked if they faced discrimination, Hardeek and Sukhdeep said:

Hardeek: I can give you some examples. So when I first moved here, there were quite a few white people in Brampton at the time. So when I was growing up, I had a couple of friends who were also South Asian Punjabi guys. These [white] kids, they probably didn't know what they were saying at the time, because kids are kids right, but they will call us Paki. We would get into fights with them here and there. That was like example one [...] Second thing was on a bus. A drunk guy, of Caucasian descent, threw beer on a South Asian person and that caused a fight on the bus too. So that is the second form of racism that I have encountered.

Sukhdeep: I think that is the norm here.

Hardeek was involved in fights because he would be called Paki. Calling any South Asian a Paki can lead to a fight. In Hardeek's examples, he was called Paki during his teenage years, by other teenagers. Scholars Muninder K Ahluwalia and Laura Pellettiere (2010) argue Sikh children are especially vulnerable to harassment and bullying. Sikh youth are likely to be called derogatory names and be involved in fights because of those terms. Other age groups in this study have also been called Paki before.

The second example Hardeek described is an example of Islamophobia that occurs in many different communities of South Asian descent. The Sikh community especially faces Islamophobia, as Sikhs are confused as Muslims, and Muslims are confused as terrorists (Ahluwali, 2013). For example, Balbir Singh Sodhi was the first person killed due to Islamophobia after 9/11 (Paur, 2008). Stories of physical assault were less common than other forms of discrimination in this study, such as verbal assault. Physical assaults, however, do 
occur. Stories of physical assault circulate within the Sikh community. In Hardeek's example, the drunk Caucasian guy had thrown beer at the South Asian man because he has brown skin. The Caucasian man entered the bus, approached the South Asian male and immediately thrown his beer onto the South Asian male. Afterwards, the Caucasian guy made racial slurs towards the South Asian male. Hardeek was brave enough to intervene and got the drunk Caucasian guy off the bus.

In similar scenarios, others will not intervene, or another person will not be around to intervene. In these situations, it can become frightening and dangerous, especially if the person involved does not know how to de-escalate the perpetrator(s) or does not have the opportunity to do so. In Ahluwalia and Pellettiere study, some of the Sikh men they interviewed were beaten up (Ahluwalia and Pellettiere, 2010). The prevalence of Islamophobia can cause much harm, as was the case in Harkeek's example.

Sukhdeep argues Hardeek's experiences are typical in Canada. For Sukhdeep, community members have commonly faced a racial incident. As a person of Sikh descent, it is not shocking to find stories of racial discrimination. Stories of outright discrimination circulate within the Sikh community. In this dissertation, two-thirds of the participants faced discrimination or witnessed a racial incident. Some of these incidents included witnessing racism to fellow community members, racial slurs made to the participants, beer bottles thrown at the participant to fights that happened because of racial insults. Participants can be impacted negatively by their experiences, depending on the frequency and severity. The following excerpt represents Hardeek and Sukhdeep's impact from their racist experiences:

Gurdeep: How did the really racist experience make you feel?

Hardeek: Well you feel like, like you do not belong. 
Sukhdeep: Even though you are born and raised here, they kind of make you feel like an outcast.

Hardeek: Yea like even when you hear the word Indo-Canadian as to Canadian. Like

I understand that I am of East Indian descent, but I am still Canadian before Indian though. That in general puts you in a category.

Hardeek and Sukhdeep felt alienated from their racial encounters. They felt as if their appearance categorized them as outsiders, though they were both raised in Canada. They both discussed earlier how those teenagers who called them Paki were kids and probably did not know any better. Hardeek's and Sukhdeep's incidents still impacts them, and it frustrates them that they encountered it. Canada is considered a mosaic of cultures, but these racial experiences do indicate race can impact treatment Brown men get from others.

\section{$\underline{\text { Institutional Racism }}$}

Like what has been happening in America with the police, the police officer that had quit. They had planted a gun on him so that they can do him in. [...] This type of discrimination, that's dangerous. [...] The organized discrimination, the one that the establishment has created, the one in the organizations.

Gurdial Singh

Organized discrimination has lasting life impacts on the individual who faces it. The fellow officer will shatter the ex-police officer's life if the ex-police officer is charged for possession of the gun that the fellow officer planted. The participants were able to describe examples of institutional/systemic racism that they witnessed or had happened to them. Based on patterns, participants described two types of institutional discrimination. They are future opportunities and current treatment by establishments and services. 


\section{Institutional Discrimination: Future Opportunities}

Participants highlighted various barriers that prevented future leadership opportunities. One of the participants named Gurjeet was involved in Jagmeet Singh's NDP leadership campaign. Gurjeet witnessed much systemic racism during Jagmeet's campaign. When asked if he faced discrimination in Canada, Gurjeet had said:

Gurjeet: Systemically, working through this campaign, yea we did. Like this campaign we didn't even realize what it meant to be a person of colour and how we had to work twice as hard to get the same thing. Right so its apart of this campaign we had won in everything across the board. Despite that there were more attacks on anyone else, they were like racialized attacks. The Terry Milewski thing happens. So you feel that, you feel like even though you have achieved so much, you are still treated as the other.

Gurdeep: I get that feeling, it's like systemic racism...

Gurjeet: It is systemic, its still going to take maybe another generation of people to like get used to it. But at this point, you feel it. You know especially being in national politics, with an idea of media and communications, you see it.

As Gurjeet had explained, there were clear signs of systemic racism during Jagmeet's campaign trail. Jagmeet faced systemic barriers that other candidates did not, such as questions of whether his appearance would ruin the NDP's election chances or hecklers who would appear at Jagmeet's rallies because he was a racial minority candidate. Race impacts the evaluation of candidates (Redlawsk, Tolbert, and McNeely, 2014). These barriers can deter minorities from attempting a leadership position. After being elected, Terry Milewski on his CBC show called Power and Politics questioned Jagmeet about the 1985 Air India bombing. Although Jagmeet 
had nothing to do with that incident, Jagmeet was depicted by Milewski as having relations with the bombers. Milewski demanded Jagmeet to condemn the bombers on live television. Other federal leaders, such as Prime Minister Justin Trudeau and other politicians attended Nagar Kirtans (a Sikh parade) where the pictures of the Air India bomber were displayed, just as Jagmeet had. Jagmeet received more criticism than his fellow non-Sikh politicians. Sikh politicians, such as defense minister Harjit Sajjan were questioned about this incident because they were Sikh. The Sikh community bore the brunt of the blame for the actions of a few during the Air India bombing (Jakobish, 2014). The media racializes Sikh politicians as sympathizers and supporters of the Air India catastrophe. For a volunteer like Gurjeet, it is frustrating to witness racialized attacks against their candidate. Running for politics is an example of how Sikh males faced barriers towards leadership roles. The Sikh community faces systemic barriers towards achieving different leadership roles.

Participants also argued community members are denied employment opportunities because of systemic issues. Gurdial is a passionate advocate towards this issue because of barriers that he and his family have faced, as well as barriers that Gurdial had seen others in the Sikh community face. Gurdial is a university educated person from India. He is very qualified and yet faced many barriers to prove he was so in Canada. Currently, he owns a successful business, but only after many difficulties as an immigrant to Canada. During the interview, Gurdial explained how he had to take many tests, though he already had the qualifications from India. The examinations wasted a lot of Gurdial's time and delayed his process of finding a steady job to support his family. When asked about this type of discrimination and bias, Gurdial said: 
This type of discrimination is a lot. Like for no reason write an English paper, [write] a math one, that one, none sense! When you write your assessment one year ago, what will happen in the second year, in one year will you forget? [laughing]. [...] Like when you learn Punjabi, does this mean by the next year you will forget? From this year to the next, you will be [giving] fees again? That is nonsense, all these barriers they have made. [...] Oh, the leader of the union, he was a puller, our Indian. He said in our profession get the students to sit with us, do the same qualifying tests they give us to the kids $[\ldots]$. It was so hard, that students from here usually do not know. It's just for this reason. Then there are these small things, to do your assessment they will take two years. For two years, eat a lot of hardships.

Gurdial's explanation describes how Sikh immigrants face barriers to finding employment in their field. Gurdial and other immigrants had written tests they already passed when they lived in India, such as speaking English. These tests had taken a considerable amount of their time and resources. Sikh immigrants still had to work somewhere to provide for their families while they waited to write their tests. Those jobs tended to be hard labour jobs that did not pay well. Some of the qualifying tests Sikh immigrants were forced to write were difficult. Gurdial contends many Canadian born students in the same field as the immigrants would not pass the qualifying tests. The tests have been made challenging to prevent immigrants from finding excellent employment opportunities. Gurdial claims Canada wants Sikhs for their labour, not their expertise. Judge (2003) argues Sikhs were welcomed into Canada because their immigration became a necessity for labour purposes. Sikh immigrants have a hard time finding jobs in their area of expertise because of systemic issues. 
Participants, especially the older participants complained that professional positions such as policing and municipal administration underrepresent Sikhs. The older participants argue barriers prevent community members from professional positions. According to scholars Ahluwalia and Pellettiere (2010), the Sikh community faces discrimination in the employment sector. A Sikh's identifiers, such as their turbans, accent, ethnicity, and skin colour made impacts towards their hiring process (Ahluwalia and Pellettiere, 2010). For example, Ahluwalia and Pellettiere discussed an example of where an employer offered a Sikh male a job on the phone but denied the Sikh male that opportunity when they appeared in person (Ahluwalia and Pellettiere, 2010). Stories of higher work standards for promotion and extensions of a contract, being fired for a minor reason compared to their coworkers occur from my experience in the Sikh community. Some participants in this study argue discrimination in the workplace impacts the Sikh community's future opportunities.

\section{Institutional Discrimination: Treatment by Services and Organizations}

Participants complained about different treatment by establishments, in services, and by those who have positions of power. Jeet Singh was a participant who faced discrimination in the workplace and by a person in a position of power. Jeet Singh studied nursing for his undergrad degree. For his degree, Jeet Singh is required to take a placement in an Ontario hospital. He faced difficulties finding a placement for his nursing program, as he has a beard and refuses to cut it for religious purposes. Hospitals require their nurses to shave their faces entirely to wear an airtight mask. Some hospitals in Ontario will make exceptions for religious purposes while others will not. Other fields of work make exceptions for wearing a beard, such as the Canadian army. The field of nursing does not give this exception. Jeet eventually found a placement. 
However, during his placement, Jeet was not treated fairly by a security guard at the hospital. This passage describes issues Jeet had when he returned to the hospital from his break:

So sometimes I would walk there, grab like a coffee and come back. Then the security guard would be like I need to see your id and I am like you had saw me leave, you see me coming back, like how many people are coming back at 2 o'clock in the morning. I still show it, but stuff like that, that I would consider as like they at the same time, you would see other people that looked differently, they would never get stopped. Like why are you stopping me?

The security guard forced Jeet to show his ID every time he returned to his workplace. The security guard did not require Jeet's peers to show their id. Jeet was treated differently than his peers by the same security guard in the same scenario. Jeet, like other participants, was monitored and treated differently because of his appearance. Another participant named Harjeet complained that a security guard was racist towards him when he visited a shop. Paur (2008) argues turbaned bodies are profiled more. Those who are not American, are to be watched, monitored (Paur, 2008). In Paur's words, "to monitor the turban and the body to which it is attached-reflects the joint operations of ocular, effective, and informational profiling (Paur, 2008, 69)." As Sikh males are different, they will be monitored more severely by security profiling practices. These joint operations of profiling become common, such as profiling in airports. These systemic issues can cause hardships and annoyances towards Sikh males.

Sikh males were also treated differently in a variety of different settings. One of the participants, named Sukhi, described a variety of places where he felt he was being treated differently than his peers. Sukhi said: 
I see different treatment when we go to certain restaurants. So higher class, profile places. Also, I think I have been treated differently by the authorities. Categorized as a wrongful doer just because of the presentation of the clothing that I wear, or either by the colour of my skin. I have been treated differently or been treated less then others of a different ethnic background.

Sukhi is a young male of our community who preferred to wear baggy clothes and hats. In Sukhi's example, high-class establishments are telling an aspiring Sikh youth that he does not belong. His authority figures example included teachers. He gave an example of how a teacher looked at him negatively for the bangles he wore, which is a part of his cultural attire. His authority example also included treatment from police officers. Sikhs such as Sukhi face different treatment because there are some misunderstandings of different cultures in Canada. Judge (2003) argues there is a differential cultural understanding of European immigrants and Indian immigrants. Perceptions of Canadian identity view Indian culture as out of place. Parmjit S Judge (2003) describes an example in which an individual asked a ninth generation Canadian of Indian descent about his experience living in Canada to that of India. Perceptions of Canadian identity does not recognize Indian descent as a traditional trait of Canadian identity, though Indians have been in Canada for over a century. There is a hierarchy order of cultures in Canada (Judge, 2003). This hierarchy views racial minorities with less value. Sikhs such as Sukhi will be treated differently and negatively because of this hierarchy.

Systemic issues in policing impacted a few of the participants. A few of the participants complained about systemic issues when police services were required. An example is of Harbhajan, who was born and raised in Canada. One of Harbhajan's experience that occurred in 
Guelph, Ontario required police officers. The police mistreated Harbhajan. This passage describes Harbhajan's view and experience of racial profiling in Guelph:

We were in Guelph and there has been a lot of racial profiling around there in the Guelph area, that I am aware of. And that a lot of people are starting to get aware of, are understanding how the cops are thinking over there is a white supremacy town [...]. We got into an altercation between a white party and us, and it was them, that first started the altercation and we were in a poutine shop. And the funny thing is, it all turned around onto me and my cousin. Me and my cousins actually, actually being arrested and being detained and put into a drunk tank and getting a ticket as well because of this. And this altercation happened with them assaulting me first, and that was on camera.

Harbhajan and his cousin faced penalties for an incident that others of White decent had created. Harbhajan and his cousin were defending themselves. The police officers could have used video evidence to lay charges. Instead, the officers assumed Harbhajan and his cousin started the incident and blamed them for it. Harbhajan believes the Guelph police are racist and targets minority groups. The participant Sukhi argues, "I have seen this happen so many times, where a White person would start a problem with another person and automatically it was the coloured person's issue." In Sukhi's and Harbhajan's experiences, the police were more likely to blame minority groups for an incident that was not committed by them. Stereotypes of different groups impact officers' quick judgment (Carroll and Gonzalez, 2014). Because of this, police officers are more likely to blame minority groups for crimes that they did not commit, which is evident in Harbhajan's case. Systemic issues impact services the Sikh community receives from policing. 


\section{Conclusion: Discrimination is an Issue in The Sikh Community}

In conclusion, the findings of this section are that the Sikh community, from this sample representation, view Canada very positively. In general, those who immigrated to Canada are happy that they immigrated and those born and raised in Canada are appreciative of their country. However, members of the Sikh community do face hardships because of discrimination. Historically, negative views and attitudes towards the Sikh community impacted how Sikhs were treated, such as racial slurs aimed at Sikhs during the 1980s. Currently, some racial attitudes that impacted discrimination historically are still prevalent to some extent. Participants who were immigrants faced discriminatory practices because of negative attitudes towards immigrants. These types of attitudes, sometimes coming from those within the Sikh community who were born and raised in Canada, can lead to the feeling of isolation. Some of the participants faced overt discriminatory practices, which included verbal slurs and physical aggression. In some instances, assaults would lead to fights. In other instances, participants faced institutional discrimination. Institutional discrimination impact job opportunities, leadership opportunities, and quality of services to the Sikh community. In this section, around seventy-five percent of the participants were able to identify some form of discrimination that they either faced or had witnessed, outside of their carding incident. To conclude this section, the Sikh community is one that faces discrimination. The next section will be analyzing the participants' stories about their street check experiences. 


\section{Chapter 4: Carding in The Sikh Community}

Carding has remained a controversial issue in Canada, though Reg. 58/16: Collection Of Identifying Information In Certain Circumstances - Prohibition And Duties had been introduced in Ontario to regulate the practice. Controversies were most evident during my attendance of public consultations on the new street check regulations in Brampton and Ottawa. The majority, if not all the attendees, want carding to be banned entirely, not regulated. The attendees argued carding led to adverse outcomes and racial profiling. In academia, numerous scholars have argued racial profiling is prevalent in policing. Scott Wortly (2003) discussed a survey that asked 3,500 Toronto high school students whether they have been stopped and searched by the police in the past two years. The survey found that police officers stopped and searched $40 \%$ of Black students while officers stopped and searched 17\% of White students (Wortly, 2003). Wortly (2003) argues many Black youths who do not commit any criminal activity are frequently stopped by police, in comparison to White youths (104-105). Scholars such as Comack (2012); Owusu-Bempah and Wortley (2014); Roberts and Doob (1997); and Tator and Henry (2006) argue Black Canadians and Aboriginals face racial bias in the criminal justice system. However, scholarly articles that depict the Brown communities' experience towards street checks are difficult to locate, though the media has discussed the communities experience. The Toronto Police Service have carded 1.8 times the Brown youth population of Toronto (Rankin and Winsa, 2012). The Brown perspective was also missing during the public consultation sessions. Numerous Brown folks do not like discussing their experiences publicly. This chapter has partially filled this void by discussing the Sikh perspective towards carding.

A Sikh male's carding experience tends to be different from another Sikh male's carding experience. Some carding incidents happened on the street while others have happened in a car. Some faced it in high school while others faced it when they were in their fifties. Some were in a 
group while others were by themselves. Some were told that they matched the description, others were falsely told that they broke some rule or had a car malfunction. Some encounters were lengthy, while others were short. Some participants had a turban, others wore baggy clothes, while a few were dressed professionally. Some were born and raised in Canada; others immigrated to Canada later in their life. Many factors influence and impact a person's carding incident. However, there are some general patterns towards these experiences. This dissertation divides those general patterns into four categories. The four categories are random pullovers, carding on the street, searches, and abuse of authority.

\section{$\underline{\text { Random Pullovers }}$}

The first general type of carding experience participants faced was random pullovers in a vehicle. Many participants faced this type of carding, as many of the participants live in commuter cities and travel in cars for large portions of their time. When a police officer pulled the participants over, the participants had known that they did not violate any traffic law. According to scholars Charles R. Epp, Donald P. Haider-Markel, and Steven Maynard-Moody (2014), during a traffic stop a police officer picks out extremely bad violators whereas, during an investigative stop, police officers target people who look suspicious (Epp, Haider-Markel, and Maynard-Moody, 2014). For this reason, many of the participants felt targeted by police officers. An example is of Fateh. Fateh was in his early twenties during the time of the interview and was around that old when he was pulled over. He was driving back home from work late at night. Fateh did not commit any offence, but the officer pulled him over regardless. This passage details what happened at the incident: 
As I was waiting at one of the red lights, I saw a police officer pulling out of a plaza. Once the lights turned green; she started tailgating me for about five minutes until she finally decided to pull me over. When she walked over to my door I asked her why I got pulled over, she said because my left side brake light had a fuse. So, I got out of my car and checked but the light was working fine so I showed her, and she made up other things for pulling me over.

The officers gave the Sikh males false reasons (in a few instances, no reason) for their random pull over so that the police could investigate them. A broken tail light was a common excuse. Fateh proved the officer gave a false reason. In most cases, participants were too scared to prove they were pulled over falsely or were not able to in their incident. In other instances, police officers continued towards their investigation, as was the case in Fateh's experience. After Fateh proved the officer wrong, the officer conducted an outside inspection of his car to see if she could find a car malfunction. Then the officer attempted to search the inside of the car, but Fateh was able to prevent it because he knew his rights. Fateh believed he was pulled over because of his appearance for wearing a hoody and a cap, as well as playing music in his vehicle. The police pulled Fateh over on the assumption he violated a law, over knowing that he violated a law.

In other random pullovers, police officers blatantly lied to the participant about their pullover. An example of this is Avneet, who had been randomly stopped in Brampton two to three years ago. According to Avneet:

I was just driving here in Brampton, and I was coming home from a friend's house. This was around twelve, one in the morning, so it was nighttime then. And it was an empty road; I was by myself. And yes, I did have a black car, but I did not have a tinted car. He said I was driving above the speed limit; I didn't think so, wasn't in a 
hurry to get home. [...] He said you were speeding, and then I said sorry sir, I thought I was going the speed limit. He said let me see your insurance card and everything. I showed him everything, and he was quite rude about it. And he took longer then he needed to, I mean like you just punch in the driver's license and insurance to see if it's working, and you go. You put your name in CPIC and you see if they had any prior history. However, he took a very long time, like twenty-five to thirty minutes. He comes back and asks where are you coming from, and I was like I am coming back from my friend's house. He was like were you drinking anything tonight, and I was like no sir. He then asked were you smoking, and I was like no sir, I do not smoke. And then he said, get the hell out of here.

Avneet later revealed that he knew he was not driving fast. The officer was tailgating Avneet for a few minutes before he pulled Avneet over. If Avneet knows there is an officer following him, Avneet is not going to speed. Just like Fateh's reason, Avneet's pullover was false. Avneet, like some of the other participants, was worried he would get into trouble. Thus, Avneet did not argue back to the officer. The police officer wasted a lot of Avneet's time. Some stops are longer than Avneet's stop; other stops are shorter than Avneet's stop. Each stop wasted a considerable amount of the participants time. Some participants were late to their daily functions, such as work, because of their random pull over. In instances such as Avneet's, the officer tends to be rude and aggressive. In Avneet's example, the officer made many assumptions of Avneet such as he was drinking and smoking. His assumptions were false.

Participants can become frustrated by their carding experience. An example is of Paul, who witnessed two carding incidents. His first incident was similar to Fateh's experience while the second one was similar to Avneet's experience. Paul was annoyed by his second carding 
incident as the officer had no evidence to prove he and his father were speeding. Paul knew he and his father drove under the speed limit and was annoyed that the officer gave a false reason for the pullover. According to Paul:

They always seem to have a reason for pulling us over. It wasn't like they said, this is a random stop. They never said that. They always pull up a reason, even if the reason doesn't exist. They always try to have a reason for pulling us over. It's not like they are saying this is a random stop and then we could associate that with carding, and associate that with targeting the community.

Almost every carding incident had this issue. In other instances, the officer never provided a reason. As a researcher, this is frustrating as it becomes difficult for community members to know if they were carded or not. The current carding regulations in Ontario does not apply to those who are driving. The policy does not recognize random pullovers as carding. Because of the frequency, patterns and the methods of the pullovers, the police are investigating those drivers who did not commit any criminal offense. According to Epp, Haider-Markel, and Maynard-Moody (2014), during random stops, the police officers have decided to conduct a criminal investigation by fabricating a reason for the stop (Epp, Haider-Markel, and MaynardMoody, 2014). The Black American community was more likely to be randomly stopped by the police than the White community (Epp, Haider-Markel and Maynard-Moody, 2014). For this reason, the Black American community had a much higher pull over rate than the White community. The Black American community was not committing more traffic violations. The Black and White communities had committed about the same amount of traffic violations. In fact, according to a self-reporting study, participants in the White community were more likely to report that they sped than participants in the Black community (Epp, Haider-Markel and 
Maynard-Moody, 2014). Police assumptions on who will commit a crime impacts who gets randomly pulled over. Participants are frustrated as the police targeted them. The participants know others are committing traffic violations, but officers pulled them over when they did not commit an offence.

\section{Carding on the Street}

Officers carded many of the participants on the street. The participants' carding experience on the street was different from the participants' random pullover carding experience. According to Howard F Mortan (2015), an expert on random street checks, officers would claim they were conducting a criminal investigation when they carded an individual (Morton, 2015). Police officers usually gave the participants a criminal investigative reason when they carded participants on the street. An example is of Hardeek and Sukhdeep. Hardeek had gone to Sukhdeep's birthday gathering. After the gathering finished, Hardeek and Sukhdeep began to wait for Hardeek's mom outside, a few houses away from Sukhdeep's house. When asked if the police ever stopped them, they had this to say:

Hardeek: Me and Sukhdeep did get stopped by the police one time, together. I was at Sukhdeep's house and basically, we were just hanging out. We were on the corner of the street, I was waiting for my ride to pick me up. And cops rolled up in a... Undercover cops came, in a dodge charger, black colour. So, the funny thing is, I don't smoke weed, I don't do drugs. And when they stopped us, they started questioning why we are here, what are we doing here?

Sukdeep: And I literally just live like 10 seconds away. We were almost right in front of my house. 
Hardeek: Like three houses away from Sukhdeep's house, so... What happened was that they said that there was a suspicion of drug dealing going on. So, they definitely got our IDs out, started searching us. And the funny thing about that search was that it was a full-on pat down, like full search, emptied out our pockets and everything. So I had a rag cloth in my back pocket. And he opens up the cloth and says what are these crumbs, as if there is crumbs of marijuana on my cloth. And I am like, how would I have crumbs of marijuana in my cloth when I do not smoke weed or if I do not sell weed. So that was pretty fishy. Like that was blatant outright, he was blatantly accusing me of having drugs on me when I do not even use drugs and that stuff.

Hardeek and Sukhdeep were both waiting for Hardeek's mom to pick up Hardeek. The officers, however, accused Hardeek and Sukhdeep of possibly being drug dealers. Hardeek and Sukhdeep were both forced into a pat-down and forced to empty their pockets when they did not commit any offence. According to Morton, those who face a street check usually are given a pat-down as well (Morton, 2015). This was a typical pattern in this study, especially when an officer carded the participant on the street. Officers usually accused those who faced pat-downs of conducting criminal activity. In Hardeek's and Sukhdeep's case, the officers accused them of drug dealing and possession of marijuana. The officers were aggressive towards their carding instance, which is common when carding happened on the street.

In other instances, police officers would stop an individual because they claimed the person matched the description of someone they were looking for, such as in Jeet's incident. Jeet was in high school at the time of his incident. On the day of his incident, he and a friend were traveling back to school, after getting lunch. To get back to school, they went through a ravine. A 
police officer happened to be at that ravine and called Jeet and his friend over to him. This passage describes Jeet's incident:

This one incident, there was a cop car there. I don't know if they were looking for somebody, or they were just stopping people, but they stopped me, and a friend of mine. And they asked me questions about who I was. I had my school id and everything, and I told him who I was. And they kept asking me do you know this guy. $[\ldots .$.$] The person that they were referring to, then they kind of told me that I$ looked like that guy. And then I at that point showed them my ID. I am like I am this person and on my ID it says I am this person. And like well, [officer asks] what classes do you have today and I told him that, bio. I remember I had bio, chem, advanced functions and I had physics. [...] Didn't know they had access to our grades and stuff. They pulled out our grades, [...]. And it was literally after midterm, and uhm, I wasn't doing so good in physics. [officer] 'You should be going to your physics class more, and paying attention. You're getting a 68 right now, that's not really great, you're not going to get into university with that.' And I am like, ok I don't know why you are telling me this, but sure.

The officer in Jeet's scenario was very aggressive. Jeet was bothered that he continuously got asked if he was a specific individual or knew that specific individual. Jeet showed his ID to the officers and proved he was not that particular person. Afterward, the officer asked Jeet about the classes he was taking. Police officers do collect school information when they card (Morton, 2015). The officer brought up Jeet's grades, which is not relevant to the purpose of the random stop. It was bizarre that the officer brought up Jeet's grades. Jeet did not commit any offence and was shocked that the police randomly stopped him. The police officers in these scenarios are not 
involved in any criminal investigation. The officers are instead arbitrarily stopping individuals who are law-abiding citizens (Morton, 2015). The purpose of this practice is to record information for potential leads to crimes. The officers had gone beyond this in many of these instances.

\section{$\underline{\text { Random Searches }}$}

A disheartening finding of this study was that almost half of the participants faced a search, such as a search of the individual, or an attempted search of their vehicles, at least once in their carding experiences. A few of the participants faced multiple searches. This study never anticipated finding this outcome. I was shocked to find numerous participants discussing a random search experience. A few of the participants recognized that it was normal for the police to conduct random searches in Canada, though its illegal. Gurdial is a participant who faced a random search. Gurdial was born and raised in India, immigrating to Canada in the early 2000s. Gurdial has experience with both the Canadian and the Indian police. One day, Gurdial went to pick up his kids from the high school they attended. While he was waiting for his kids, a police officer drove up to him and searched his car. This passage describes Gurdial's experience:

I had just parked my car; it used to be a CRV. And police person came and put his car right next to mine and said get out of the car; I got out. Said show your car, I showed him my car. He said open your trunk; I opened my trunk... He is not allowed to tell me to get out of my car. Nor could he check my car. It was totally illegal! Nor could he had said open your trunk. That was totally Illegal! It was wrong, but for me, it was like, it's not like I have done anything wrong. I opened everything, go have 
your look. But it was wrong. You should have some reason to ask me to ask these things right.

This passage further explains the view Gurdial has towards random searches, as well as view members of the community have towards random searches from the stories that he has heard: [speaking very calmly] Yea I have heard stories, but normally people do not complain. We think we have nothing to hide, let them do what they must do. And we are like used to it. Even back home [India], nobody really minds. You can be stopped at any place and you can be checked. When we came from that area, body search and everything was working over there. It was normal.

Gurdial was forced out of his car while the officer searched his car. The search did not concern Gurdial because he knew he had not done anything wrong. Gurdial knows that he cannot get in trouble. Gurdial has nothing to hide and knows the officers are not going to find anything on him. He has become accustomed to body searches and argued others in the community are as well. It was normal for illegal searches to occur in India, so it was not a surprise when he and other community members faced it in Canada. The normality of facing a search is a factor towards why some in the Sikh community do not speak out about their experiences. Those Sikhs have become accustomed to searches. However, Gurdial opposes this police practice. He argues the search was illegal and complained about the incident during the interview with much passion in his voice. According to Gurdial, "it's a mental torture!" Gurdial's incident distressed him. He had a hard time sleeping that night, thinking about the incident. Gurdial should not be distressed by his carding incident.

The location impacts a persons carding experience considerably. A person who faced multiple random searches on the street was Hardeek. Hardeek attended high schools in different 
parts of the Greater Toronto Area, including a high school named North Albion College Institute (NACI) in Rexdale, a suburb in the west end of Toronto. Rexdale was where much of the Sikh community first immigrated to in Ontario during the 1990s before the Peel Region became a popular destination. Rexdale still receives immigrants from the Sikh community and has a sizeable Sikh population. This passage represents Hardeek's carding experiences in Rexdale:

So when I used to go to high school in Rexdale, there was a spot beside the school, of NACI. It was called mount olive court, where we would pass by to go to pizza place, the plaza and stuff. And sometimes we would just stand there and just hang out. So there would be bike cops all the time. And they would always, not even once, not even twice, but a couple of times, we have been stopped by the police, by cops, searched for scars and tattoos. But then again, just how it was in the other area where me and Sukhdeep had a bad encounter, it's a sketch area. Fuck man, I do go to a lot of sketch areas. Well that was where my schools are, what can you do. [we are all laughing]

Me, Hardeek, and Sukhdeep are laughing because we often were at or went through 'sketch' areas. Sketch areas refer to neighborhoods that the populace views as dangerous, dubious and/or suspicious. Hardeek had to travel through sketch areas, as his schools were in these areas. Opinions of Rexdale is negative and an impoverished neighborhood. Rexdale has many racialized immigrants of diverse backgrounds. The media focus on crime coverage in Rexdale, particularly violent crime. For example, when one searches for Rexdale in google news, the majority of the articles are related to homicide and violent crime. Potter and Kappeler (2012) argue the media blurs fiction from reality. Desmond Cole, a prominent opponent against carding, argues neighborhoods such as Rexdale are focused for its crime aspects. The media does 
not focus on the positive news that comes from Rexdale (Policy \& Politics, 2016). As a person born and raised for a portion of my life in Rexdale, I can attest that a lot of positive initiatives occur in Rexdale. The crime coverage leads to a fear of crime, which justifies the use of police practices such as carding and frisks (Roberts and Stalans, 1997). Hardeek was carded a couple of times because he was a young Brown male in a suspicious area of Rexdale.

More needs to be done to prevent random searches. Section eight of the charter of rights and freedoms states, "Everyone has the right to be secure against unreasonable search and seizure (Canadian Charter, 1982, s 8)." From the responses the participants gave, Sikhs face unreasonable searches. Numerous young Sikhs dislike discussing their search experience, so they will not discuss their experiences publicly. Many Sikhs are afraid to fight against their experiences, while others do not want to come out.

\section{$\underline{\text { Abuse of Authority }}$}

A few of the participants in this study shared appalling stories. These stories are the exceptions, but they do occur. As discussed earlier, police officers can become aggressive and will make false claims. In the searches section, police officers assumed the participants committed a crime and began searching them without knowing whether they did or not. A worse incident occurs when a police officer charges for a violation that never occurred. This can cause much financial loss. Harjinder faced this. Harjinder was fifty at the time of this interview. Harjinder is an immigrant from India and recently bought a brand-new Bentley work truck during the time of his random police stop. Harjinder was annoyed and angry at his experience of carding. During the interview, he was loud and angry when discussing his experiences and his view towards police pulling over members of our community randomly. He was given traffic 
violation tickets and had to appear in court for his random pull over. This passage describes Harjinder's random pull over experience and his experience of going to court:

He [the police officer] had stopped someone else on the road; I had passed him. I do not know what he had noted but after stopping to talk to him, he had stopped with the other person and had come up behind me. So, like after 2-3 kilometers, 4 kilometers along afterwards he had stopped me. [...] Asked me for my license and my insurance. And I gave it to him [...] He gave me a ticket for the inspection sheet, for which there should be a case for it. That was my fault that I did not fill out the inspection sheet. Then second, he gave me a ticket for being overweight, which it should not have been made. Thirdly, he said I can take your plates off, of the truck, that it's a Bentley truck. And I said, take it off. And then he said, no I will let you go [...]. And I had fought the ticket, but it did not get forgiven [...] Yea had to pay the full, and he [the police officer] had came to court.

The police randomly pulled over Harjinder. The officer initially stopped someone else. Harjinder explained how he only had a few items in the back of his truck; thus it could not be overweight. The officer falsely gave Harjinder a ticket. The police officer falsely threatened to remove Harjinder's car plates. Similarly, a few other participants received false threats to make them comply with the officer. Harjinder was angry that the officer pulled him over when he did not do anything wrong, that the officer gave him a false ticket and that the officer threatened to take his car plates off. In total, Harjinder lost eight hundred dollars. In the words of Harjinder, "it's a huge money." Eight hundred dollars will impact Harjinder and his family. Harjinder could have used that money for a variety of reasons, such as family, vacation, and living expenses. Those who do not have the same established resources that Harjinder has will face considerable 
issues because of their pullover. Harjinder has his own successful business, so he will not be impacted as negatively as someone who is a low wage worker. Harjinder's scenario is an example of institutional racism that creates barriers towards a successful life. Harjinder should not be given a false charge over a false pull over.

When police officers have the authority to stop individuals randomly, physical violence can occur. An example was of Sukhi when he was thirteen years old. Sukhi was coming back from a birthday party and was walking outside with two girls who would walk back home with him during the time of his interaction. A police officer spotted him and demanded him for his ID. Sukhi refused to and tried to walk away from this incident. This passage explains what happened to Sukhi when he tried to walk away:

Sukhi: One time I had honestly tried to walk away from it. Oh my god, I felt like I was going to get beaten up that day! Like why would the police officer, the way he grabbed me and turned me around, he threw me on the hood. You know it was horrible.

Gurdeep: He grabbed you and put you on the hood [I am shocked]!

Sukhi: Yea maybe when I was thirteen or fourteen. He was like; he took me home when he pulled my record, he realized that I was 13 . He thought that I was 20.[...] He had to go drop me off home because I was too young, he couldn't have had done that to me. But at that time we did not have no understanding that we could have went....

Gurdeep: You were $13 \ldots$

Sukhi: I don't want to be searched, leave me alone. So I start walking away and the guy threw me down. 
Sukhi was thirteen at the time of the incident. A police officer should not treat a minor the way Sukhi was. The officer assaulted Sukhi when he threw Sukhi onto the hood of the police car. The officer also threw Sukhi's jacket to the floor. Sukhi did not commit any offense; he was walking home from a birthday party. The officer believed he had the justification to grab and throw Sukhi until he found out Sukhi was thirteen years old. The officer had to drive Sukhi home when he realized he assaulted a minor. Sukhi was traumatized by this and is frightened to know an officer can treat him the way that they did. The Supreme court ruled individuals have the right to walk away in an experience such as Sukhi's. Morton (2015) argues courts tend to assume civilians know that right. Majority of civilians do not know this right, especially the youths. Youths often feel intimidated and obligated to comply with police officers, because of the police officers influence (Morton, 2015). Sukhi should be able to walk away from the officer. In this example, Sukhi was not able to and was forced to comply. As a thirteen-year-old during the incident, Sukhi did not know what he could and could not do when a police officer approached him.

The following two examples occurs when police officers become aggressive during a carding practice, especially when officers are searching for charges. These aggressive practices occur in Canada because of the racialization of minorities, such as of Sikhs. According to scholar Elizabeth Comack (2012), race is socially constructed through the process of racialization. Racialization is not an issue until negative meanings are attached to a minority group, which causes racism. These racial views become so normalized that individuals attach members of a minority group with negative values (Comack, 2012). Applying racialization towards policing, police officers will act differently towards minorities because of the inherent differences. The officers may not be trying to be racist in every scenario, but their normalized views impact their practices. Racialization means Black Canadians are more likely to be pulled over, searched or 
seized. The racialization of aboriginals is a reason why aboriginals face starlight tours. Aboriginal men are stereotyped as drugs users, and aboriginal women are stereotyped as prostitutes (Comack, 2012). Within the Sikh community, the participants discussed a few stereotypes the police view them as. Stereotypes include Sikhs race a lot, drink and drive, sell drugs, are in gangs, and do not know how to drive. With this viewpoint, police officers will then act upon themselves to tackle these so-called "issues." Because of racialization towards the Sikh community, a few Sikhs have faced bad experiences like the ones stated above. The participants were randomly pulled over randomly or randomly stopped on the street because the officers assumed that they are committing a crime or will be committing a crime.

\section{Conclusion: Carding And The Broader Sikh Community}

In summary, the Sikh experience towards carding is very diverse based on context to context. From scenario to scenario, different factors influence a Sikh's carding experience. Overall, the Sikh community tends to view their carding experience negatively. The participant's experience to carding is however apart of the broader Sikh collective experience towards racial profiling and discrimination. The Sikh community of Canada has witnessed policies that directly targeted the community because of security concerns. This thesis will first analyze policies that restrict a Sikh's use to the kirpan and security measures towards a Sikh's turban. It will then compare those policies to carding.

In contemporary Canada, there is a hysteria towards Sikh's articles of faith after the events of 9-11. Balpreet Singh (2013), the legal counsel for the World Sikh Organization (WSO), discusses the impacts 9-11 had on the Sikh article of faith, the Kirpan. In November of 2001, Ste-Catherine Labouré school in Montreal denied twelve-year-old Gurbaj Singh Multani an accommodation to his kirpan. The superior court ruled in favour of the accommodation, but the 
Quebec court of appeal overturned the decision. The Quebec Court of Appeal referenced a shifting in security concerns after 9-11. Balpreet argues, "for the Quebec Court of Appeal, while the kirpan may have been accommodated in 1990, the same accommodation could not be made in the world of 2001 (Singh, 2013, 52)." Similarly, VIA rail removed Balpreet from its train because he wore a kirpan and VIA rail considered it a weapon. Hypocritically, VIA's policy allowed hockey sticks, skates, bats, and provided first class passengers with steak knives for meals (Singh, 2013, 53). VIA has a clear double standard towards what was considered a security concern and what was not. These events indicate how 9-11 influenced the concerns of the kirpan as a security concern. Multani eventually received accommodation but only after he won his case in the supreme court of Canada. Two weeks after the Multani case, VIA would change its policy and accommodate kirpans, but not before VIA received human rights complaints (Singh, 2013). Canada would become more accepting of the Kirpan, but only after much campaigning for the article of faith. There are still issues around the Kirpan in Canada, such as its ban in the National Assembly of Quebec.

Policies have also targeted the turban because of security issues in Canada. As noted in the literature review, in the name of security, the Transport Security Agency (TSA) in the United States violated a Sikh's constitutional right with extra pat downs and secondary screening (Deal, 2011). In 2015, the Canadian Air Transport Security Agency's new procedures made it mandatory for a secondary security screening of turbans and other religious headgears (Singh, 2015). Many Canadian Sikh travellers complained about facing extra security measures, such as pat-downs of their turbans and checking for explosive residue. One such Sikh traveller named Raj Singh Hundal argued, "Since April 15th, 2015, I believe I am being racially profiled and targeted as a security threat in Canada because of my faith and my turban (Singh, 2015)." 
Canada quickly revoked this policy after much public pressure. Canada originally introduced this policy to align it with that of the TSA. These policies are a clear infringement to a devout Sikh's right to freedom of travel and freedom of religion. The populist is more accepting of these constitutional infringements because of the fear of national security (Deal, 2011). Policies such as the banning of the kirpan and extra checks of the turban are clear examples of how the law is used to monitor the fear of the brown body.

In comparison to carding, many of the participants felt that the police were racially profiling them. They felt that excuses were made to pull them over unjustly. Sian (2017) argues that after 9-11, Sikh bodies have been problematized with harsher profiling and policing measures directed at racialized populations. In the Sikh participants' experiences, police monitored Sikhs due to the fear that they are breaking the law or will be breaking the law. Police searched many of the participants under the assumption that they are hiding something or that they are a dangerous individual. Sian (2017) argues the visibilities of differences consume western societies to govern and regulate racialized populations. The war on terror has led to an increase of surveillance of 'dangerous' brown bodies (Sian, 2017). Thus Sikh males, whether they wear all articles of faith or not, are monitored more harshly due to being viewed differently and being viewed as a dangerous brown body. The ban on kirpans, the extra security checks of turbans, and the profiling of Sikhs during carding are all caused by the fear of brown bodies. Carding of Sikh males is another part of the Sikh communities collective experience toward profiling.

Carding is also apart of the broader Sikh's experience towards discrimination and belonging in Canada. Historically, perceptions of the Sikh community accuse Canadian Sikhs of being against Canadian interests. White Canada accused pioneer Sikhs of stealing jobs from 
White Canadians (Johnston, 2005). Racial policies were made to prevent Sikh immigration and to increase deportation of Sikhs in Canada. Similarly, after the Air India bombings, the Sikh community bore the brunt of accusations towards the bombing (Jakobish, 2014). The Canadian government would refuse to accept Sikhs as asylum seekers during the Punjab insurgencies and after the massacres of Sikhs in Dehli during 1984 (Tatla, 1999). The Canadian government would only accept them as economic migrants. The Air India episode continually resurfaces and accuses the community of harboring extremists. For example, Immigration Watch has campaigned to prevent Sikh immigration. Immigration Watch circulated posters which depict a group of Sikhs in India protesting. The poster portrayed the Sikh community as a dangerous one and argues policies must prevent further immigration of the community. The Sikh community continuously faces backlash towards their place in Canadian society. Sentiments in Canada dictate who belongs and who does not.

Currently, the Sikh community is accused of committing a variety of crimes. Carding is used to monitor those accusations and assert who belongs in what spaces. Some of the accusations towards the Sikh community I have encountered from the media, participants, and random civilians includes extremists, rapists, violent, backward, oppressive, dangerous, gang affiliated, and drunk drivers. Police officers also depicted some of these views during the carding incidents, such as drinking and driving when the driver had no signs of drinking and driving or drug dealing when officers had no evidence to prove they were drug dealing. Carding is used to monitor a "potential threat." The context of an individual makes a difference between who gets pulled over and who does not. Carding to Sikhs happens more in low-income areas, areas perceived as dangerous, to larger groups, and with other racialized individuals. The state uses carding, like exclusionary policies before it, to monitor a Sikh person's daily functions. The next 
chapter, the discussion chapter, will dictate how the participants carding experience impacted them. 


\section{Chapter 5: How Carding Shapes Sikh Males}

In the previous chapter, this thesis explored the different experiences participants had when they were carded. This chapter discusses the participants' perception of their event, the practice and the police. Police relations with the public are important if policing is to be effective. Policing requires the ongoing support and voluntary cooperation of the public (Murphy, 2009). Murphy (2009) argues part of the cooperation and support comes from the evaluation civilians give to policing during their police encounters. This chapter will discuss how carding impacts police-community relations with Sikh males. This chapter first explains the emotions participants have during carding. Analysis of the participants' emotions will answer how the participants perceive their carding incident. The second section explores the participants' views towards carding. The third section describes the impacts carding had on the participants. The fourth section discusses how participants view policing, specifically because of carding. The last section of this chapter explains changes the participants want towards carding.

\section{Emotions in a Random Street Check}

The participants had a few different emotions when they were carded. Some of the participants were frightened. These participants were scared the officers would charge or punish them, though they did not commit any offence. Avneet was initially scared when he was randomly pulled over. Avneet thought of every scenario that could impact him negatively, such as his insurance increasing. Randy argues community members forget about their rights because they are scared by their incident. Randy argues community members quiver and gives nervous replies when officers pull them over, which makes them look more suspicious. Balvinder is one such community member. Balvinder discusses how he and others give a quick yes and no responses, hoping the police will leave them alone quickly, without them getting in trouble. The 
officers tend to be aggressive during their carding incident, which further escalates the scenario, over deescalating it. An example is of Sukhi and Harbhajan, who were scared into letting the officers search their car and their pockets. They were threatened to be taken to the police station if they did not comply. Sukhi argues, "They are terrifying you into wasting another day of your life with a [police] station, being harassed by cops all around you. That is something that you do not want." These sorts of scare tactics have occurred in some of the participant's experiences of carding. These scaring tactics do work in many instances because the participants fear the consequences they may face from the threats. Thus, carding can be scary, especially when officers make false threats.

The feeling of being scared in some instances does not just end in the carding scenario. Few participants are worried and scared that the groups they hang out with, or any activities they do may lead them to a random stop. An example Harbhajan discussed was his paranoia of going outside to smoke. He is worried that he will be stopped and questioned by the police when he smokes a cigarette. A few of the participants are traumatized by their carding experience, and their trauma continues into their daily lives. As Sikhs, they are a part of collective diaspora's experience of trauma, violence, and loss. The Sikh community has a complicated history with trauma. The Dehli riots of 1984 traumatized the Sikh community and the political climate after 9/11 in North America retraumatized Sikhs (Verma, 2006). Those who faced and survived the Delhi riots have seen loved ones killed, a hateful populace, and a complicit police force who refused to intervene. Das (2006) discusses how the violence became so fabricated to the social that it becomes indistinguishable from the social (165). The trauma resurfaces as fears in everyday lives. Sikhs recount their traumatic experiences through collective remembrances of 1984, which become grounds to remember other events that impact the diaspora, such as 9-11 
and profiling (Nijhawan \& Arora, 2013). Carding can create another traumatic experience for a Sikh male.

Another feeling participants described was of anger. Some participants were passionate and angry during the interviews because of their experience. It was evident in the participants' voices during their interviews. Anger occurs because the participants are frustrated with the way that officers are treating them. In these scenarios, the participants want to argue back to the officers because they feel the officers treated them unjustly. One good example is of Randy, who was pulled over by the cops randomly in many instances. Randy detests officers pulling him over when he did not commit any offence, and he especially does not like being accused of committing an offence when he did not commit an offence. He would fight back with the cops because he was frustrated by the officer's treatment. When Randy was wrong, Randy would humbly accept any penalties that he deserved and apologize. However, if he were not, Randy would fight back. His motto is own up to your mistakes but stand up for yourself when you did not make a mistake. For example, in one incident the police officer was aggressive initially and said that Randy was driving $100 \mathrm{~km}$ per hour in a $40 \mathrm{~km}$ per hour zone on a narrow road. That is logically not possible, as Randy said the car would fly off the road. Randy argued back to the officer, yelling at the officer to stop lying. His friend later recorded the incident, in which the officer retracted his statement. Randy did not like false accusations and threats being used against him by the police. Some of the scholarly studies towards racial profiling described examples of where participants became less compliant as they continued to face carding. Elizbeth Comack's (2012) book discussed a famous example of Mathew Dumas. Police officers randomly stopped Dumas on a few occasions before his shooting. On the day of his shooting, the police force was looking for a person whom they claimed matched Mathew Dumas' description. 
Dumas was not that person, but he did not comply with officers when they tried to interrogate him because Dumas was frustrated by his previous interactions with police officers (Comack, 2012). Events following would lead to his shooting. The feeling of anger can retract participants from wanting to comply with officers.

The last feeling participants discussed was the feeling of annoyance. Annoyance usually happened to participants who had prior experience to carding during their pullover. They were annoyed because they believed the officers targeted them. These participants argued their carding incident was a waste of their time and the police officer's time. An example is of Paul. Paul was pulled over randomly with his father in his second carding experience. This description describes some of Paul's experience:

He pulls us over and he said that you guys were speeding and I was like, wait a second, we were going 40. And I think the limit had been saying 50 on every road and he was like no you guys were clocking 60. I was like wait you don't have a radar gun. And then he was like so license and registration and you be quiet. And I was like, that's nice. [....] Didn't want to say anything to make the matter worse. So after he left, I was like, what the fuck, like mind my language but what the fuck. He just randomly pulled us over, going 40 and then said that we were going 60 .

In this incident, Paul was annoyed because he faced another random stop. Being told that they were going ten kilometers above the speed limit when they knew they were going ten kilometers below the speed limit is a clear example of the officer targeting Paul and his father. The police officer had no evidence to prove Paul and his father were going above the speed limit. Since the officer is an authority figure, Paul was forced to comply. Paul was a participant that did argue 
carding is not completely bad, but he is annoyed that he faced another random pullover. Paul believes officers could have better used their time by stopping someone who was speeding.

The participants' frustrations and annoyances towards carding are a part of the larger Sikh Diaspora's frustrations and annoyances towards the treatment the community receives. There is not a single homogenous experience that defines the collective Sikh experience (Nijhawan \& Arora, 2013). Many factors influence a Sikh's experience that makes it different from another Sikh's experience, but there are linkages towards their experiences. A carding experience, for example, will be different towards another person's profiling experience, such as at the airport, just as a Sikh's carding experience on the street and a Sikh's carding in a vehicle was different. Regardless, there are some linkages towards these experiences, such as the motives behind profiling in airports and carding. Nijhawan and Arora (2013) discuss how this leads to a "constellation of individual, yet linked, experiences surrounding family, gender, racialization, transnational histories, citizenship and class and affectivities these categories illicit (316)." The Sikh community is frustrated with the labels Canada has assigned, just as the participants are frustrated for being blamed of a crime they did not commit or will not be committing. The Sikh community views differences towards how their bodies are monitored and regulated, such as the injustices in Canada's immigration system (Nijhawan and Arora, 2013). The Sikh Youth have been active in creating new spaces and new movements against the injustices of Canada (Nijhawan and Arora, 2013).

In summary, participants from the Sikh community perceive their carding incident negatively. A wide variety of emotions impact the participants, depending on the scenario. Some participants are scared because of the potential outcome. Other participants are angry because they are frustrated with the way they were treated in their incident. Finally, many of the 
participants are annoyed by their interaction because they believe the officer targeted them for their random police stop. Overall, the Sikh community does not perceive their random street check incident well.

\section{$\underline{\text { View of Carding }}$}

The view participants had towards carding varied from person to person. The majority had negative views of carding, while a small minority of participants argued there are positives towards this practice. This dissertation will discuss both competing views. The few participants who have some positive views of carding argue that carding is for community safety. They argue police use carding in some instances to find potential criminals or solve potential crimes. Paul, for example, has some positive views towards random street checks in his first incident. In his first incident, Paul was seventeen and his brother, who was driving, was nineteen. Paul and his brother were pulled over randomly by the police while they were driving home. According to Paul's perspective: "I don't think it was a complete waste of resources because there have been incidents were G1 drivers have been driving on the road and stuff, and that has led to an accident or something." Paul does not disapprove of his first random police pull over, as to him, the police officers may have thought that they were underage drivers. Paul finds it an issue that unqualified young drivers are driving and making the roads more dangerous. He believes carding is a way to prevent potential car crashes. However, Paul, just like every other participant had some form of criticism towards this practice. Paul described how the police will card to prevent reckless driving in Rexdale, but will not do the same in other communities, such as Woodbridge. When comparing police practices in Rexdale and Woodbridge, Paul had said, "In our area, there are a

lot of Brown peoples so, they do that kind of stuff. In those areas, people miss stop signs right in 
front of police officers and they do not do anything." From his experiences of Rexdale and Woodbridge, Paul argues racial bias impacts which neighborhoods face police stops. Rexdale has a large racialized population, while Woodbridge does not. He argues communities with a large South Asian populace will face carding, while communities with a sizeable White populace will not. Neighborhoods with positive views are trusted more than neighborhoods that do not (Gorbunova et al, 2015). Thus, these participants do view positives to carding, but argue more needs to be done to prevent the negative impacts.

Almost all the participants viewed carding negatively and ineffective. In contrast to Paul's argument, Hardeek argues:

I wouldn't say carding is effective at all. Carding of anyone, of that matter. A criminal is a criminal. A criminal that does not have a race or religion or a colour, of some sort. If you want to find a criminal, you get it from the roots. You can't just approach random people, assuming they have drugs on them. Or they are up to no good.

As Hardeek has stated, any person can commit a criminal act. Officers card individuals, under the assumption they are committing a crime, without knowing that they committed a crime. The police will be successful in a few instances but at the cost of annoying the populist and breaking the populists charter rights. The majority of the time the police will not be successful in finding anything, as was the case in this thesis project. In comparison to a similar stop and frisk practice in New York City, the police were not successful at finding weapons and counterbonds in majority of cases (Krupanski et al, 2009). Instead, the participants, such as Sukhi and Harbhajan, argue that the police use investigative excuses to target them, rather than solve an actual crime. This passage describes excuses Sukhi and Harbhajan have heard police officers use: 
Sukhi: Suspicion haha. Strictly I have heard the word we have suspicion. We have suspicion, suspicion that you have something on you. We have suspicion that you guys have been doing something. Somebody had called us and said...

Harbhajan: Yea

Sukhi: We have heard all, any excuse that you can think of. We have heard this is a very similar vehicle.

Harbhajan: Yep yep. Oh, you guys fit a description of something that had happened. Like you know oh...

Sukhi: When you give someone your height. Like I look at the person and said there about 75 million people of my height. [I am laughing]. What are you talking about?

Harbhajan: Yea, exactly right. Or somebody we are looking for a Brown male that's six foot, and how many Brown people are six foot?

Officers gave Sukhi and Harbhajan a variety of different excuses that did not fit the context of their actions. In one example, the officers frisked Sukhi, Harbhajan, and their friends while they were playing basketball and relaxing at a park. The officers told them that there was a robbery in the neighborhood. Logically, this excuse did not fit the context of what Sukhi and Harbhajan were doing. Being told that they were in a similar vehicle, that they fit the description (without explaining the description), or that they have the same height is not enough of a reason to associate Sukhi and Harbhajan with a crime. These excuses were used to justify carding and searching Sukhi and Harbhajan.

The participants also argue carding is a practice that harassed and targeted their community. Balvinder is one such participant. According to Balvinder [in an annoyed tone], "In our Indian community, it's more like 99\% they stop us more." From Balvinder's worldview, the 
police are continually stopping members of the community to harass them. Balvinder argues police officers purposely annoy community members. He argues this because of the experiences that he has faced with police officers as well as the stories he knows from others, who had been randomly pulled over. For Balvinder, random pullovers are typical in the Sikh community. The Sikh community does face racial profiling due to the fear of national security. Mann (2017) argues Canada targets Sikh immigrants for security concerns. Canada views Black and Brown bodies as a threat to Canada, specifically those who are Arab and Asians. Canada introduced laws to control immigration flow and monitor the activities of immigrants. These laws viewed foreign nationals and terrorists as the same. These laws have wrongfully profiled many young individuals who belonged to ethnic and religious immigrant groups (Mann, 2017). As a Sikh immigrant, Balvinder's experience is a part of the Sikh immigrant experience of being targeted by the state. Balvinder's worldview was the most extreme of all the participants. Many of the participants instead argue that the Sikh community is more likely to face carding, with some arguing other communities, such as the Black community face it more.

Overall, most of the participants view the police practice of carding negatively; that carding targets the community as officers view community members as wrongdoers. Participants argue officers should not have carded them, as the participants tend to describe themselves as good law-abiding citizens. Many participants feel as if the police are wasting resources when they are randomly stopping them and at times, randomly searching them. They feel as if this practice is an abuse of their civil liberties. Almost all the participants agree that being randomly stopped is a human rights violation. Most participants felt that carding is not an effective strategy, or that they are not sure whether carding has any effect at all. The majority feel as if carding targets their community, with some arguing police target other communities by this 
practice, such as the Black community. A few feel as if this practice could be used to solve crimes and used to make the community safer by finding bad folks in the community. However, they also see many disparities towards how officers use carding currently. Overall, the participants viewed carding as a harmful practice towards the Sikh community.

\section{Impacts Carding Has on The Community}

Carding has led to negative impacts towards the community. The majority of the participants described some negative impact carding had on them. Psychologically, carding impacted participants such as Balvinder. Balvinder felt shameful because of his random pullover. This portion of the interview is Balvinder's response towards the question, how did the carding incident impact you:

Balvinder: Impact $[s i c]$ is going to happen, when you look at the fact that others go by and they look at they [the police] pulled over a criminal [...]. That really impacts us. When you had done nothing, their lights are on you. Are you not going to get impacted, when all others go by you and think, what are they thinking?

Gurdeep: I will say yea, you are scared when...

Balvinder: Exactly, when you are on your own, inside its like, we feel that for no reason, they had just [pulled us over]. What are others going to think, relatives or how others are going to view you.

For Balvinder, it is difficult imagining how random civilians would view him when he was pulled over. Random civilians' perception of Balvinder's impacts him. Balvinder knows random civilians blame him as the guilty party, as the criminal, not the police officers. The Canadian Sikh community has a history of being blamed for producing crime because of their culture, such 
as gang activity. Nijhanwan and Arora (2013) discuss how there is a moral panic of Sikh youths and gangs. The broader Canadian populace has blamed the culture of the Punjabi Sikh community for the prevalence of youth violence. The broader community viewed it as a failed social integration by second-generation Sikh youths (Nijhawan and Arora, 2013). This simplistic view does not account for actual causes of youth violence. Depicting deviant Punjabi youths in the media instead scapegoats the Sikh community as the cause for gang violence. The Canadian populace will shame a Sikh such as Balvinder as the criminal without accounting for the context of his pullover, just as how a portion of the Canadian populace has shamed the Sikh community for gang violence.

Participants, however, found it more shameful when a fellow Sikh witnessed their carding incident. Sikhs, especially those from India, are rooted in the value of izzat (honour) (Nayar, 2004, 47). Participants were worried how fellow community members would judge them and talk about them to others in the community. Fellow Sikhs impact the reputation of the participant when they view the participant negatively. It is especially frightening when fellow community member the participant knows witnesses the carding incident. Sikh youths especially are scared their parents will learn about their carding incident. We Sikh youths do not want others to judge us as criminals, and we do not want to get in trouble by close loved ones for something that we did not do. For this reason, many in the Sikh community do not like talking about their experiences. These experiences can traumatize the participants. Sikh males often felt shameful because of their carding event as the males are blamed for the carding incident and are labeled a criminal.

Carding can also impact a person's future. Two of the participants, who hold important positions witnessed how community member's lives had been directly affected by this practice. 
The two folks who had seen the impacts are Gurjeet and Sukhi. Gurjeet's position exposed him to impacts carding had. Gurjeet found that carding denied employment opportunities to minorities. According to Gurjeet:

People get carded overwhelmingly that belong to minority groups, and they get denied opportunities in the future, for no reason what so ever. That for me is like the biggest issue. Right so like you could be, you are in a position where both your parents are laborers. You work your ass off to go to university, that you did a masters, a Ph.D. whatever. You got yourself, you have the skills that people want to pay for. And then you go for a high-end job, and then you are denied that job based on a carding situation, I don't know how long ago.

Gurjeet has heard of complaints from individuals who had been denied employment opportunities because officers carded them in the past. When an individual who faced a carding incident applies for a high-end job, they will have to get a security clearance to work. When an employer does a criminal background check, they will find that the individual does not have a criminal record but, their records indicate the police have stopped them on different occasions. The employer becomes suspicious about the individual and in turn, denies that individual of an employment opportunity. A racial minority is more likely to be carded, so they are more likely to be denied a job opportunity because of the carding incident they faced. This is systemic discrimination. As Gurjeet has mentioned, this creates hardships for immigrant and racial families from achieving positive social mobility.

For the Sikh community, this finding represents another barrier towards achieving employment. The Sikh community continuously fought against attitudes that systematically denied them opportunities, such as positions in policing. Baltej Singh became the first turbaned 
Sikh police officer in the early 1990s, but only after fighting for the inclusion of his turban and considerable backlash from the populace, including retired RCMP officers (Judge, 2003). In my attendance of the 2017 Sikh Symposium at Carleton University, Baltej Singh discussed how individuals in anonymous letters would threaten him for becoming an RCMP officer and how communities would attempt to prevent the RCMP from posting Baltej Singh in their community. Contemporarily, racialized minorities such as Sikhs are underrepresented in policing. In the Peel Region, a region with a sizeable Sikh presence and a population that was 60 percent minorities in 2011, racialized minorities only represented 13 percent of the police force in 2010 (Grewal, 2015). In 2015, racial minorities only accounted for 15.5 percent of the police forces hiring's. There is a clear bias towards hiring racial minority police officers. A few of the participants want to become police officers. Their carding incident may impact their application to become a police officer. For example, a Black Canadian named Knai Singh was denied participation into the Toronto Police Force's ride-along program for his law school program. Although he has no criminal record, his multiple carding incidents with at-risk youths prevented him from participating in the ride-along program (Rankin, 2016). Singh's carding instances impacted his opportunities with policing. Carding may impact a Sikh's future opportunities, such as a job in policing. Further research is required to understand the implications of the complaints Gurjeet discussed. Carding might be another barrier that prevents a Sikh to professional employment.

The second future impact carding has is that it can make a youth rebel and can lead to legal trouble. Carding will increase barriers for that individual to achieve a prosperous life. As a person who works with youths and as a person who has been carded by the police on several occasions, Sukhi has seen how policies such as carding can impact youth's behavior. According to Sukhi: 
The enforcement and the fear that they have to strike in us actually causes us to rebel more, especially with the youth. When they [youths] are seeing that this hard authority pushing down on us, in the same instance as if their parents were pushing down on them, they will rebel. And I think that's a thing that starts at an early age in certain neighborhoods. It carries on throughout all the stages. That's why a higher level of crime is in certain neighborhoods because simply the people at a young age start rebelling. It carries on with them to adulthood.

Youths will rebel if the police are constantly monitoring them by practices such as carding. Sukhi has described the delinquency theory that is known as labeling theory. According to scholar Donald Shoemaker (2010), in labeling theory, a person becomes a delinquent because of labels individuals assign them. The label changes how that person views them self and that individual starts to act accordingly to the label that has been assigned to them (Shoemaker, 2010). Therefore if youths face many incidents of carding, the youths are often told that they are a suspicious individual. Those youths will begin to believe that they are criminals and will begin to commit delinquent acts. Sukhi explained how he had older role models who guided him out of those negative feelings. However, Sukhi argues many youths do not have older role models who will help guide them out of their negative feelings. As a person who works with youths, Sukhi has seen how carding breaks a youth's confidence. Constantly facing carding can break a person's confidence, specifically a youth's confidence. They start losing confidence because they start to view themselves as someone who has less value, which will impact their future ambitions. Being labeled as a criminal can lead a person to commit a crime in the future, which can then potentially give them a criminal background. Carding has the potential to impact a person's future negatively. 
The final impact this thesis project will discuss is the impact carding has on the participant's trust towards the police. Generally, the participants tended to have some impact on their trust in policing. The impacts varied in which some participants had shown smaller trust impacts while others had significant trust impacts. The smaller trust impacts were participants describing how they will be more careful when they view and interact with police officers. Smaller trust impacts occurred when the carding experience was a small negative experience, such as not facing a random search. An example is of Avneet, who was randomly stopped by a South Asian police officer in the Greater Toronto Area. According to Avneet, "I guess it made me more wary of Peel Regional Police over here. It made me pay attention to them a bit more. I guess cops here are stricter than outside the GTA. Like based on my experiences." Avneet had friendly encounters with White police officers outside the GTA. Because of his experiences with carding, Avneet said he would be more careful with officers from the Greater Toronto Area and Brown police officers in comparison to White police officers outside the GTA. Avneet also argues that if he is going to get pulled over by a Brown police officer, who is going to treat him like a 'dick' the second time, then the third time, Avneet says, "I will be a dick too." For now, Avneet has minor impacts towards his trust in police officers, but it can be impacted more severely if he faces more carding incidents and more severe carding incidents.

Contrarily, some of the participants lost much trust towards policing. Officers carded Harbhajan on numerous occasions, and his carding experiences tended to be negative. He also has some very negative experiences towards policing when he needed them. Harbhajan's experiences have impacted him negatively. When asked if he trusted police officers, Harbhajan said: 
Say if I had seen somebody going around maybe like going messing around somebody that I don't know in my neighbor's house, on the front door or something, I would go outside and personally go out there. I wouldn't go first thing and call the police.

Harbhajan does not trust officers. In a scenario where he should call the police, Harbhajan would instead try to solve the crime himself first. This is a distressing issue as the primary role of the police is to deal with criminal activity. Elijah Anderson (2000) conducted a study on a poor racialized neighborhood in Philadelphia. One of the findings he found was that many of the residents there do not rely on the police. They would instead go themselves and stop a break and entry for example then call on the police to do so. Residents do not trust the police, as they feel ostracized and marginalized by the police force, so residents believe that they must fight for justice themselves (Anderson, 2000). A few informal sets of practices known as the code of the street governs the neighborhood. The majority of participants were not on this spectrum but in some way, their trust in police officers had been negatively impacted. Their faith in policing, however, can become like Harbhajan's if they face the same experiences Harbhajan had. Carding in some way will impact the faith a Sikh male has towards the police force.

In summary, carding is a practice that impacts the Sikh community. The impacts vary towards person to person based on the context. The carding experience can lead to psychological impacts on the participant because of the fears that they start having. Participants are worried that others will have negative views of them and label them as a criminal. Carding has the potential to impact a person's future negatively. There have been claims that carding has denied community members employment opportunities, as the criminal record shows the person has faced multiple police stops. Also, carding could influence individuals to conduct criminal behaviour as carding 
labels those individuals as a criminal. The label will impact their future. Finally, this practice impacts the trust participants have of police officers. Some of the participant's trust had been impacted slightly, while others had lost much trust towards policing, with a few who would avoid using the police if possible. Thus, carding negatively impacts the Sikh community.

\section{Overall View of Policing}

After exploring how carding has impacted the Sikh community, specifically how carding has impacted the trust participants have towards police officers, this chapter will now discuss the participants' views of the police. These views reflect the views of those Sikh males whom the police have carded, not of all Sikh males. Overall, the participants tend to find Canadian police officer more favorable than police officers from other countries. For those participants who made comparisons, they tended to make comparisons to police officers in India and the United States. They argue the police practices in India and the United States of America are notorious compared to what the police practices are in Canada.

The view towards policing in Canada varied from person to person. A few of the participants had very positive views of police officers overall. An example of this is Avneet, a participant who wants to become a police officer once he has completed his schooling. He completed a police foundation course and currently studies an undergrad degree at a university. He knows a lot of the troubles that police officers face and has described it during the interview. This passage describes the negative experiences that a police officer will face, according to Avneet:

On the regular, the five percent they [police] deal with, they usually [will say to the police officers] "f u pig," you know very negative people. They deal with very 
negative people, you know the low lives [...]. Like the low lives, people who are stuck in their regular routines, not going, above and beyond drugs, alcohol $[\ldots]$ and fights. [...]. It's a stressful event for them to, the cops are humans too. Behind the uniform, it's just another citizen who is trying to restrain another citizen.

Avneet argues police officers have a difficult job. Avneet argues that when a civilian has a rude interaction with a police officer, it might be because the officer dealt with a rude civilian prior. The police officer may have fought a civilian or restrained someone who was conducting criminal activity. Police officers are humans as well, and many joined policing because they want to make the community safer. Because of all the negativity a police officer deals with, Avneet contends a police officer faces much stress. Some of the participants were thus sympathetic toward police officers. Some of the participants had very positive stories and experiences about policing. Some of the participants in this study have viewed police officers positively overall.

However, other participants in this study have negative views of police officers. As mentioned previously, carding impacts participants trust in officers in some form, with some of the participants viewing policing very negatively. There is a connection with the participants' experience of carding and how they view police officers. An example is of Harjinder who, as was discussed earlier, had an extremely negative experience with his random pull over. An officer pulled him over in an incident in which he should not have been, and the officer gave him two tickets, which he did not deserve. He, along with other participants found Canadian policing to be hypocritical. These participants argue the police force charge civilians for breaking the law, while officers will not be. According to Harjinder: 
[very angry] I saw a police officer in uniform, drink and drive. [...] I saw at the same bar, he was drinking, and we were drinking, and he was in a uniform. And he came out; we came out also. And what I saw, he was sitting in a police car and driving, away. If a civilian does this type of mistake, it's a mistake. If a cop does that, it's not a mistake. Why is that?

Harjinder is angry, as he believes police officers abuse their authority and police agency will not punish those officers for breaking the law, such as by drinking and driving. Police officers have been caught drinking and driving. According to Poisson and Mclean (2015) of the Toronto Star, from 2010 to 2015, 60 police officers were caught drinking and driving in Ontario (Poisson, and Mclean, 2015). Disparities participants have seen include, officers drinking and driving, officers using their cell phones when they drive, officers driving much faster than everyone else, and officers using their sirens only to skip red lights. Combining the disparities with the participants carding experience made some participants view policing negatively. Harjinder, for example, views police officers very negatively because of the disparities he has seen within policing and the negative experiences he has faced by police officers. Harjinder had passionately argued, "Why he can [sic], he has a two mind, or he is special made from god?" Harjinder is arguing that Canadian police officers are not above civilians and therefore, they should be held accountable for breaking the law and abusing their authority. Harjinder feels that the current police practices need to change. Harjinder argues India's police system has more corruption then Canada's police system. However, Harjinder argues there is some corruption in Canadian policing. Some of the participants have very negative stories and experiences about policing. Some of the participants in this study have negative views of police officers because of that. 
Harjinder was on one end of the spectrum while Avneet was on the other end of the spectrum regarding their overall view of policing in Canada. The participants fell within the Harjinder and Avneet spectrum towards their overall view of policing. Overall, participants had criticisms towards policing because of their carding incident. Participants do want to see improvements in Canadian policing. Those who participated in this project had all faced carding, with many facing negative policing experiences. Due to carding, the participants on average had negative views of the police. As Sikhs are more likely to be carded, they are more likely to have negative views of the police than a White Canadian. According to Scott Wortley and Akwasi Owusu-Bempah (2009), racial minorities have fewer positive views of policing in comparison to White Canadians. This disparity is because overall, racial minority groups more likely believed police officers have biases in their practices compared to White Canadians (Wortley and OwusuBempah, 2009). In this thesis, participants complained about police biases and discrimination. Though this thesis cannot speak for the entirety of the Sikh community, this thesis demonstrates that those in the Sikh community who do get carded view biases and discrimination in policing and as such, view policing more negatively than the average Canadian.

It is crucial for local police forces to build trust with the Sikh community, as the Sikh diaspora faced a history of police bias. The Sikh community witnessed 1984, in which the police forces were oblivious towards Sikhs during the Delhi genocide. The police generally made the mobs stronger, instead of preventing the mobs from attacking the Sikhs. During the Punjab insurgencies, 'random' disappearances often happened to Sikhs by the police. A famous Sikh activist named Jaswant Singh Khalra exposed how the Punjab police murdered 25,000 young Sikhs. Officers murdered Khalra for his activism work. The Canadian police department is different from the Indian police department. All the participants recognize that the police force in 
India and the United States is worse than the Canadian police force. However, a few of the participants made parallels of Canadian policing to that of Indian policing, such as of random searches and corruption in the police force. Some immigrant members of the community have fragile views of policing due to their experiences before coming to Canada. Sikhs will not be trusting of the Canadian police if they feel there are similarities towards Indian police. A carding experience can harm trust towards police officers.

In summary, carding is a practice that impacts a Sikh male's view of police officers. Some of the participants do have favorable views of police officers. They see them as agents who are trying to make the community safer. They see the difficulties that police officers face, so they have sympathies towards them. However, other participants have many criticisms with the police force. They feel as if the officers break the law and mistreat them. These folks feel as if the police force is purposely targeting the community with practices such as carding. Participants lost some form of trust towards policing because of their carding incident. Some of the participants still have positive views of police officers. However, within this group, some find that police officers were harassing them. As discussed in the impact section, participants can lose faith in the officers to the point that they do not feel comfortable using police services when they need to use police services. In this sense, carding is a harmful practice as it deteriorates community relations with the police.

\section{Views of What Needs to Be Done About Carding}

After discussing the feelings of carding, view of carding, impacts of carding, and view of policing overall after carding, this chapter will now discuss the participant's recommendations towards carding. Almost all of the participants believe not enough is done to prevent carding and 
that politicians have not done enough towards carding. Participants may partially feel this way because many of the participants did not know about the new regulation. Some of the participants did not know what carding was until I explained it. According to one of the participants named Avneet, most people do not know that its illegal to be pulled over for the driver's license, insurance, and ownership. Many of the participants feel as though police biases are rampant when officers decide whom they are going to pull over. The few participants who do know about the issues surrounding carding on average argue not enough has been done to prevent carding. An example is of Avneet, who argues:

Carding still happens. Like you know what I mean. You brought in a policy but if there is no way to enforce or there is no oversight. Without oversight, it is very difficult to say that carding has been prevented, when there are claims of carding still being made.

The previous chapter discussed how police officers fabricated reasons to justify pullovers of Sikh males. In the few other instances, the police officer never gave a reason. The officers never told the participants their random stop was for community relations or carding. Without proper oversight towards the new Ontario regulations, officers will continue to fabricate reasons for the pullover. Also, without proper oversight mechanisms, it will be difficult to know if carding has ended or not.

All the participants wanted to see some change towards the current carding practice. A tiny minority of the participants wanted to see an evolution towards carding. These participants did find that there are benefits to carding, that it made policing easier. They argued the practice needed to evolve, to ensure officers respected civilian's rights. An even smaller minority of participants argued that nothing could be done about this, as nothing has been done about this 
before and that trend will continue because not enough folks care. However, the majority, as in almost all the participants, argue that the police practice of randomly stopping them without proper justification needs to stop. Some of the participants were very passionate about this topic, arguing ferociously during the interview that this practice needs to stop. Other participants discussed solutions to hold police officers accountable for their actions.

The participants made many recommendations to combat carding. This thesis discusses some of those recommendations below. This thesis lists its recommendation at the end of this section. Some of the participants argued the best way to end carding is to introduce body cameras on police officers. Avneet, for example, argues that in court it is the officer's word versus the civilian's word. He argues the officer's word will always win. Avneet argues body cameras will indicate whether officers are following the new regulations or if they are abusing their authority. Camera's change the behavior of others. A famous legal theorist named Michel Foucault created a famous theory towards criminal behavior called the panopticon theory. In this theory, if a person has the perceived notion of being watched, even if they were not, that person will behave differently. They become scared that they will get in trouble (Foucault, 1975). However, body cameras are a controversial issue, with studies arguing its effectiveness in policing. Some participants discussed hiring more minority members into positions of authority so that diverse perspectives are understood. Some participants argue the police should be stricter on whom they hire. They argue that the hiring process should be more rigorous than the current system. Some discuss the need to pressure the police chief to prevent carding, as the police forces listen to the recommendations of their chief. Others discussed how community leaders must fight this issue over politicians, to ensure that the community's voices are heard, and that pressure is exerted to end carding. These participants do not believe that politicians will do 
anything, but the pressure that community leaders have will stop carding. Another participant discussed how police forces should listen to the recommendations of scholars to have adequate procedures, just like how other fields such as the health sector does. Moreover, as discussed earlier, almost all the participants want to see carding banned completely.

My recommendation, after conducting this thesis is to completely ban carding, introduce a public oversight mechanism and to permit scholars to conduct studies on racial bias in policing. A complete ban of carding also includes random pullovers, as more than half of the participants faced arbitrary stops while they were in a vehicle. Regulations are not enough to prevent police bias in carding. The majority of the participants did not know new regulations were introduced towards the practice of carding or knew what carding was. The majority of the participants also do not know their rights and do not know what they can or cannot do when they are randomly pulled over by a police officer. Carding is also a violation of the participants' section 9 Charter of Rights and Freedoms, which states, "everyone has the right not to be arbitrarily detained or imprisoned (Charter of Rights and Freedoms, s9)." All of the participants' stops were arbitrary, based on the explanation given by the police. The practice negatively impacted the Sikh community and deteriorated trust between participants and the police officers. Participants argue officers should not stop civilians based on assumptions. As the stories this thesis has discussed, carding has not been effective. The purpose of carding is not proportional to the harm it causes. Carding must be banned.

Banning carding will not be enough to prevent arbitrary stops. If a law prevented police from committing an act, then almost half of the participants would not have faced attempts of illegal frisks and searches. Police officers in most cases will not face repercussions for infringing on individuals' rights, such as conducting illegal searches on the participants. For this reason, 
some of the participants do not trust police officers. A civilian oversight board is further required to hold police officers accountable for their actions. The current Special Investigations Unit (SIU) and Office of the Independent Police Review Director (OIPRD) is not suitable to deal with the participants' complaints. The board is composed of retired police officers. Currently, about 61 percent of non-forensic investigators in the SIU are former police officers, and about 67 percent of the total investigators are former police officers (Tulloch, 2017). Many of the participants do not trust police officers and will not be comfortable discussing their experiences with an ex-police officer. They will also not be comfortable discussing their issues towards someone who is pro-police. Better methods are required when hiring individuals for the board. This paper recommends Justice Tulloch's view of hiring more highly qualified investigators who do not have a background in policing (Tulloch, 2017). Increasing the diversity of the board will make the participants more comfortable in coming out to it. These boards currently are not accessible enough, as many of the participants do not know about them. The boards need to have better outreach programs so that that community members will participate in them. Furthermore, the civilian boards should have more power to hold officers accountable. In sum, this thesis argues the current Progressive Conservative Government of Ontario should cancel their repeal of Bill 175, which was supposed to begin this year. The bill would have given the civilian boards more oversight powers and would have kept the police more accountable. A competent, independent oversight board that reviews complaints made by all community agents without bias is crucial in keeping police officers accountable.

My last recommendation is to hire scholars to investigate racial bias and carding in different jurisdictions, similarly to the procedures in the Kingston study. According to Closs and Mckenna (2006), The Kingston Police conducted a study about potential biases that may exist in 
its police force, which no other police force in Canada has. An independent researcher, named Scott Wortley, told police officers to provide contact cards or data in a mobile display terminal for any stop they conduct (Closs and Mckenna, 2006). From the analysis of the data, Wortley found that young Black males were three times more likely to be pulled over than any other group in Kingston. The overall results from this study exposed disparities between police services towards different members of the community (Closs and Mckenna, 2006). Openly conducting studies towards police agencies will create a better understanding of disparities that exist in policing. Studies will create dialogues towards police forces to target racial profiling. The Kingston Police took approaches to conduct bias-free policing, which other police forces should also follow. The recommendations made by scholars should be used by police forces to limit biases and improve community relations. These recommendations are the best way to keep police officers accountable as it pressures police agencies to follow conducts.

In summary, almost all the participants want to see the practice of carding abolished. The majority of the participants view this practice as a human rights violation, which goes against their liberties, and dignities as human beings. The majority feel that the stops are unjust and officers base stops on racialized stereotypes. The majority feel as if the random stops occurred because the police targeted them, not because of reasonable suspicion. Thus, carding has deteriorated relationships with the police. If police agencies are to build community relations, they must refrain from arbitrarily stopping individuals. To ensure the process of carding has ended, further accountability mechanisms are required, such as improvements to the current civilian oversight board and research towards racial bias in police forces. From a Sikh male perspective of those whom police have carded, carding must end. 


\section{$\underline{\text { How Canadian Sikh Males in Ontario Are Affected by Random Police Stops }}$}

To answer the main research question of this thesis, on average, Canadian Sikh males who were randomly stopped by police in Ontario are affected by this practice negatively. Emotionally, a carding incident can be frightening because the participants are worried that they will get in trouble, though they did not commit any offence. Other participants get either angry and/or annoyed by this practice because they faced it before and did not want to be facing it again, or they know they were pulled over because of their ethnicity. Therefore, participants on average view the police practice of carding negatively. A few of the participants have seen positives to carding but have criticisms and thus, want it to evolve. However, the majority view the police practice of carding negatively, as the participants from the Sikh community argue that negative stereotypes are used to target them, such as the community is full of drug addicts or the community is full of bad drivers. They also view carding negatively because carding does create negative impacts, such as impacts towards the participant's psychology, their future opportunities, and their trust in justice. The participants should not have faced these negative impacts as they did not commit any illegal offence. The participants start to lose trust in the officers because of carding, with some losing much trust towards the police. Carding will thus impact the way a person interacts with a police officer, as community relations deteriorate. The goal for the police agencies is to build community relations, not to deteriorate them.

This paper will recommend that carding should be banned entirely, as the current Ontario regulations do not do that. A better independent oversight board and more independent research towards racial bias and carding are required to keep police forces accountable. The police practices of carding should be wholly banned to prevent future adverse effects from occurring to 
different communities in Ontario, as random street checks in Ontario currently affects members of the Sikh community negatively. 


\section{Chapter 6: Conclusion}

The police practice of random street checks is controversial because of the adverse outcomes it has on those who face it and because of the overrepresentation of minorities in carding statistics. In the first section of the literature review section, the thesis discussed how the Sikh Diaspora in Canada has a history of facing prejudice and racism. The Sikh community has a history of fighting for equal and fair representation of their identity. The second section of the literature review discussed how racial profiling practices impact minorities. The literature discussed how minority communities, particularly Black Canadian and Aboriginal populations are more likely to face police bias and face negative repercussions by police and the criminal justice system. For this reason, members of those communities are more likely to face random police stops, more likely to get caught and more likely to face police brutality. An example is the fact that Black Canadians made up half of the shootings by the police in Ontario, though they account for four percent of the total population in Ontario (Wortley, 2003). Issues of racism in the Sikh community has been explored in literature, though limited. The scholarly community has explored police surveillance practices, such as the practice of carding towards the Black and Aboriginal populations in Canada. However, there is a literature gap towards the Sikh population and carding. This thesis project has filled a portion of this literature gap by conducting this thesis project, How Canadian Sikh Males in Ontario Are Affected By Random Police Stops.

Chapter two of this dissertation discussed the methodological approach of this project. An ethnographic study was taken, with a focus on narratives. Ethnographies produce more indepth content than any other method which is required to fill the literature gap. Narratives provide more context about the data, which gives a better understanding of the Sikh males experience towards carding and carding's impact on the participants. This project gathered all the 
participants in the Greater Toronto Area and Toronto. The average time of interviews was around fifty minutes, interviews ranging from twenty minutes to an hour and a half. Privacy measures were taken to ensure that each of the participants was kept confidential. After this dissertation conducted all the interviews, this project transcribed the interviews and conducted discourse analysis of the data to extend the existing theoretical framework around racial biases and racial profiling.

In Chapter three, the thesis explored the Sikh experience of living in Canada to understand the influences it would have on their carding incident. Overall, all the participants have very favourable views of Canada. Participants are happy that they immigrated to Canada or they are happy that they were born and raised in Canada. Nevertheless, many of the participants encountered hardships because of their racial background. Participants faced or witnessed outright discrimination. In these incidents, individuals made racial verbal slurs or racial comments towards the participants. A few of the participants faced some physical confrontation, such as a civilian throwing a beer bottle at them or engaging in a fistfight. The other type of discrimination participants faced was institutional discrimination. Institutional discrimination was more common than outright discrimination. In institutional discrimination, the participants discussed barriers to employment opportunities. They felt that Sikhs were denied meaningful positions because of their ethnic makeup. Other participants argued that they were not treated fairly by different institutions, organizations, and individuals who hold a position of power. They felt excluded or treated differently by these entities because of their ethical makeup. One of the organizations included the police force. The participants' experiences are a representation of hardships that the Sikh community faces in Canada. 
Chapter four explored the different experiences Sikh males had towards carding. The experiences Sikh males had varied because of the different contexts in each experience. Some of the participants were old, while most were young. Officers carded participants while they were driving, others on the street, while others faced both. Some carding incidents were short interactions while other ones included illegal searches. There were many different influences, but there were general patterns towards the incidents. When carding happened in the vehicle, officers gave the participants a false reason for the pullover. Officers told participants they were driving too fast when the participants were not, their car had a malfunction when it did not, or participants were swerving from one lane to the next when they were not. These participants felt that police officers were wasting their time. When carding happened on the street, the participants were always given a criminal investigation or matched the description excuse. The participants majority of the time felt that officers were targeting them and were not conducting a criminal investigation. Many participants were also randomly searched during their carding incident. Officers either searched the participants' car, searched the participants, or both. Searches created negative views towards policing. Finally, a small percentage of the incidents were depressing. These incidents included bogus claims against the participants to harassment that the participant faced, such as physical assault. These incidents are ones that no individual should face, especially when they did not commit an offence. Thus, the Sikh experience towards carding is diverse.

Lastly, chapter five of this thesis discussed how random police stops affects Canadian Sikh males in Ontario. Many of the participants were scared about their incident because they were worried that they would face negative repercussions, though they did not commit any offence. Others were annoyed or angry about their incident because they faced carding before or 
felt the officers purposely targeted them. Thus, the participants overall viewed their carding incident negatively. A few of the participants argue there are positives to carding, but the majority do not feel that way. The majority argue carding is racist, a human rights violation, and targets members of the Sikh community. This response is partially due to the impacts carding has. Carding can psychologically impact the participants, impact a participant's future, and impact trust towards police officers. Overall, the participants view police officers in Canada more positively then officers in other countries. Some do have a favorable view of the police overall. However, the participants have complaints about officers in Canada. Almost all the participants became warier of the police force after being carded. Carding overall made participants view policing more negatively. This project recommends abolishing carding entirely instead of regulating the practice. This project recommends for an independent oversight board to judge police conduct. This project also recommends researching racial bias in different police forces.

\section{The Contribution of This Thesis}

This thesis contributes to the extant policing literature through probing the police practice of carding and its impact on Canadian Sikh males. No previous study has ever researched how the Sikh community is impacted by random police stops, though it is known within the community and in the media that random police stops do occur. It is not only just the Sikh community that carding occurs but in the general South Asian community. It is challenging to locate academic articles that discuss carding within South Asian communities. Thus, this thesis has addressed some of this vast literature gap. There are many similarities in the Sikh experiences towards other racial minority group's experiences, but there are also differences as 
well. The context of the Sikh community is different. For example, racialization impacts the Sikh community as it does to other communities. The Sikh community faces carding partially because of racialization. However, there are differences in the racialization of the Sikh community compared to the racialization of other communities such as the Black Canadian population and the Aboriginal population. This difference is partially because the Sikh Diaspora has a different history in Canada. As noted in the literature review, Sikhs have a history with Islamophobia and were viewed as the "other immigrant." The hysteria around brown bodies has led to exclusionary policies and an increase of policies in monitoring the Sikh community, such as secondary screenings at airports. Carding is another way to monitor the feared brown body. Some of Canadian society has negative perceptions of Sikhs, viewing the community as one that is not traditionally Canadian and one that goes against Canada's interest. Carding is a way to monitor the 'dissenting' community. The participant's outright and institutional discrimination stems from Islamophobia and the view of being the "other immigrant." This impacts a Sikh's carding experience as Sikhs are racialized as bad drivers, drunk drivers, into racing, dangerous, and gang affiliated.

The context of the community also impacts a Sikh's carding experience. Many Sikh families live in suburban housing areas as the community prefers big houses with open areas. The roots of the Sikh community stems from the traditional farming landscape of Punjab, thus a preference for more open space. Sikh families on average tend to be bigger than the average nuclear family in Canada, which often includes the grandparents in the same house. Driving is more of a necessity in the suburbs than a downtown urban setting. For this reason and the negative stereotypes associated with their driving, the participants were more likely to be carded in their vehicle than on the street. The scholarly focus of other minority groups such as the Black 
and Aboriginal communities tend to be on carding in the street. The Sikh community is impacted by carding differently than that of other communities. For example, some of the participants faced psychologically impacts as they were fearful of punishment from their parents for their carding experience, though they did not do anything wrong. The participants were scared that family would label them as criminals. They feared the family would see them as the guilty party, not the officer acting out in aggression. This fear was problematic in this project. It is difficult for members of the Sikh community to speak out about their experience because they do not feel comfortable to do so. The Sikh community does not have any scholarly articles written about their experiences and does not have many movements the community can relate to, such as Black Lives Matter fighting to ban carding from the standpoint of Black Canadians. Other differences include that Black Canadians on average will face carding more negatively than a Sikh Canadian would. Officers card Black Canadians at a higher rate than Sikh Canadians and a Black Canadian is more likely to face multiple carding instances. Regardless there are many similarities Sikh participants faced as other minority participants in other studies faced. For example, on average, they all view carding as a detrimental practice, they all have negative stories to share about this practice, they all discuss stereotypes used against their communities, they all feel as if their communities are more likely to get carded, and almost all want the practice to end. This paper will argue there are more similarities towards carding in the Sikh community than there are differences. This paper will conclude that the Sikh experience extends the current theoretical framework around racial profiling as this study adds another perspective, instead of changing and challenging the current theoretical framework around carding.

The overrepresentation of Sikh men in carding statistics is another example of how systemic discrimination has negatively impacted racial minorities because of racialized views. 
Racial groups face negative interactions when negative views are associated as a quality of the racial group. This includes police agencies. Police agencies thus monitor, question, and search racial minorities at a disproportionate rate. This is a factor for why racial minorities, particularly the Black and Indigenous communities, are overrepresented in criminal statistics. When a police officer has discretion to pull over an individual for investigative reasons, such as is the case with carding, they will more likely profile racial minorities. Carding has not been successful at solving criminal investigations. Instead, carding harasses civilians, particularly racial minorities as they are overrepresented.

For this reason, there is a tense political climate in Ontario towards carding and policing in general. This was most evident during the street check consultation sessions. These consultation sessions, headed by Justice Tulloch, asked the public about their experiences with carding and with the new carding regulations. The public overall at the consultation sessions wants to see more done towards the practice. One such recommendations is to improve accountability and transparency in policing. Another recommendation was to completely ban carding. Bill 175 was a good step in ensuring police forces are kept accountable towards their actions. This policy would have strengthened the oversight agencies, such as the Special Investigations Unit. The Ontario Progressive Conservative Party has however postponed the implementation of Bill 175 the day before it was supposed to be implemented. The Ontario Progressive Conservatives should implement Bill 175 in its current form. A bill was also tabled by the New Democratic Party to ban carding completely. The Ontario Progressive Conservative Party should heed to Justice Tulloch's recommendation of abolishing carding. 


\section{Limitation Of Current Work}

There were a variety of limitations that impacted this thesis project. Measures were taken to address these limitations. The most significant limitation of this project was the time constraints and the resources that were available. As this is a master's thesis, there was only a year to find participants, conduct interviews, analyze the interviews and then write this thesis. Because of this issue, I had to limit the number of participants for this study. Available resources limited the capabilities of this project. This thesis project was not funded, so the resources for this project came from my savings. I had access to a vehicle to travel within the GTA, but not in other regions. For this reason, plus the time constraints, I was limited to the locations that I could conduct this project. Because of these constraints, there were limits towards the participant pool. To address this concern, I used many different methods as I possibly could to recruit individuals and targeted diverse groups of folks to achieve diverse perspectives in the research pool. For example, I put up posters in large congregation settings, such as Gurdwara's as well as relevant local establishments, such as local Indian grocery stores. I made conversations with older individuals and younger individuals to ensure an equal opportunity based on age. Different social media platforms, such as Facebook ads and the radio were used to ensure that the most amount of folks had information about this project.

Another limitation of this project was the research topic. As mentioned earlier in this project, many folks in the community do not like to talk about their carding experience. Many folks are worried that the community will label them a criminal and worried family would punish them if their stories become public. For this reason, the potential pool of participants is limited as those who were passionate about their experiences are more likely to contribute while those who are not, are more likely to avoid participating in this project. The limited participation pool could 
skew the results of the thesis. A few steps were taken to address this limitation. As a person who is embedded into the community, I made sure to address that I have the cultural competency to conduct this project by hanging up Punjabi posters, explaining my connection to this project, ensuring that safety protocols were taken to keep them confidential and depicting that I could be emphatical towards their experiences. These steps will hopefully contain the limitations and allow for a more diverse experience towards carding.

Another limitation of this thesis was the strict requirements to be a participant in this study. This project only targeted those who identified as Sikh. Thus, it excluded individuals from other South Asian communities. This project only interviewed those who were male, who were over the age of eighteen and were carded; thus it excluded a large portion of the community's perspective about carding. This dissertation also conducted a qualitative study, not a quantitative study. The study instead focused on a smaller sample size of the population. Overall, the sample size of the study would be impacted by this. However, the small sample size is beneficial to this project. The project targeted the Sikh community because I had rapport in the Sikh community. I could speak Punjabi, which eliminated communication barriers. Sikhs, especially older generation Sikhs are more comfortable to share their experiences with me than folks from other Brown communities. It is easier to make discoveries this way. The project aims to understand the experience of those whom officers carded over the overall perspective of the community. Thus this project targeted individuals who experienced a carding incident. The project took a qualitative approach as it would provide in-depth content that is missing towards this literature gap. Thus I focused on depth, not breadth. This project acknowledges that there are many limitations towards this project which would impact the quality and the results of this project. However, I took appropriate steps to limit these limitations. Hopefully, further research projects 
will be conducted to address the limitations of this project and to address the vast literature gap towards this topic.

\section{$\underline{\text { Future Work }}$}

This dissertation highly recommends pursuing future projects related to this project's research topic. This project was only able to fill a small portion of the vast literature gap that is present. There is a vast need for better understanding of how the community is impacted by police practices in the academic sphere, as literature towards the Sikh and the South Asian community, specifically police practices towards these communities, is limited. There is also a need to research social aspects for the community outside of the academic sphere to understand how practices such as carding have impacted the community. Below are a few suggestions to pursue.

A Future project to consider is how carding impacts other South Asian communities. As reported in the Toronto Star, police carded Brown youths 1.8 times their population (Rankin, and Winsa, 2012). Thus, many South Asian communities have issues with carding, not just the Sikh community. One South Asian communities experience might be different from another South Asian community's experience. Also, the experience of being South Asian and carding, in general, could also be explored. These projects could also include Sikh women and other South Asian women experience to carding. Officers have carded South Asian women, and their experience may be different from a male's experience.

Other research topic suggestions include the Sikh community and carding in other provinces. Each Canadian province is different from another Canadian province. As such, a Sikh's experience in a province such as British Columbia (B.C.) will be different from another 
province such as Quebec. In B.C., tales such as the urban legend of Bindy Johal racializes B.C. Sikhs as gangsters. In Quebec, the fear of religious symbols has made it harder for a Sikh to practice their faith. Thus, the context of each province is different, meaning that the carding experiences in each of these provinces will be different. A researcher could also take a national approach, which contrasts the experiences of different provinces.

\section{$\underline{\text { Conclusion }}$}

From this study, I can conclude that Sikh males from the province of Ontario have overall been affected by this practice negatively. The participant's experience in carding varies from one person to the next, but overall, the Sikh males had very negative views of their experiences. All of the participants described themselves as law-abiding individuals. Majority of the Sikh males view carding as a tactic that targets the community as well as other minority communities, though there were a few who had favorable views towards carding. Participants tended to be either scared, annoyed or angry when officers randomly stopped them. After the experience, the participants identified a few negative impacts such as psychological impacts, their time, their future goals, and their trust in officers. The participants trust in officers decreased because of the Sikh males overall experience with officers, with a few avoiding the use of officers because they have minimal trust in policing. A minority want to see changes in carding while almost all participants want the practice wholly abolished. This project will recommend the complete ban of carding, due to the negative impact carding had on the participants.

The new Ontario regulations are a step at reducing carding, but the policy does not prevent carding from occurring. There are a few clauses in the new policy which are contradictory to the rest of the clauses. One of the clauses allows officers to hide information 
from the civilian they are carding, such as the primary motive for their carding incident if the officer thinks it might compromise the safety of that individual. This clause is so vague that officers will misuse it when they card an individual. The new regulation does not have a clause towards data collected before the implementation of the regulations. The data can impact a participant's future. Finally, the new regulations require better oversight mechanisms to ensure officers are following the regulations. The new policy requires police chiefs to review whether the police force is following the regulations, which is not good enough. Police chiefs are known to lie and deny the existence of racism in their police forces, from what scholarly data and media reports have reported. In this study, officers lied about the reason for the random pullovers and searches in every instance. Police officers will take advantage of the vagueness of the regulations, the lack of oversight towards their conduct and the lack of knowledge civilians have towards carding. Carding has affected the Sikh community negatively and members of other communities, particularly racial minority communities. Carding should be banned completely to prevent adverse impacts from occurring to any community. A stronger independent oversight committee is required, and more independent research towards police conduct is required to ensure police bias is not present. The committees' and researchers' recommendations must be followed by police forces to limit biases. To ensure that the Sikh community is respected and treated with dignity, Canada must abolish the police practice of carding. 


\section{Bibliography}

Anderson, E. (2000). Code of the Street: Decency, Violence, and the Moral Life of the Inner City. New York City, USA: W. W. Norton \& Company

Ahluwalia, M. (2013). "What's under There?” The Questioning of Civil Rights for Sikh Men. Journal for Social Action in Counselling and Psychology, 5(1), 45-58

Ahluwalia, M, \& Pellettiere, L. (2010). Sikh Men Post-9/11: Misidentification, Discrimination, and Coping. Asian American Journal of Psychology, 1(4), 303-314. DOI: $10.1037 / \mathrm{a} 0022156$

Ahmed-Ullah, N. (2017, June, 5). How Brampton, a town in suburban Ontario, was dubbed a ghetto. The Globe And Mail. Retrieved from: https:/www.theglobeandmail.com/news/toronto/brampton-a-story-of-politicalimportance-power-and-ethnic-enclaves/article30273820/

Bakshi, R. (2002). THE ROOTS OF GANG WARFARE: B.C.'s Sikhs must look hard at themselves, MACLEAN'S, 32-33.

Ballingall, A. (2017). 'It's about the dream': NDP supporters hail Jagmeet Singh's leadership win. Toronto Star. Retrieved from: https://www.thestar.com/news/canada/2017/10/01/jagmeet-singh-wins-the-ndpleadership-race.html

Bell, D. (1995). Who's afraid of critical race theory? University of Illinois Law Review, 1995(4), 893-910.

Biddle, C. (2016, April, 5). Muslim Profiling is Not Racism but a Moral Necessity. The Objective Standard: Reason, Egoism, and Capitalism. Retrieved from: https://www.theobjectivestandard.com/2016/04/muslim-profiling-is-not-racism-but-a$\underline{\text { moral-necessity/ }}$

Brinkmann, S. (2013). Qualitative Interviewing. New York, NY: Oxford University Press.

Bruce, S. (2018, January, 22). National Legion issues policy reminder after Sikh man told to remove turban. CBC News, Retrieved From: http://www.cbc.ca/news/canada/princeedward-island/pei-tignish-legion-turban-apology-1.4498355

Canadian Charter of Rights and Freedoms, Part 1 of the Constitution Act, 1982, being Schedule B to the Canada Act 1982 (UK), c 11

Caroll, L., \& Gonzalez, L. (2014). Out of Place: Racial Stereotypes and the Ecology of Frisks and Searches Following Traffic Stops. Journal of Research in Crime and Delinquency, 51(5), 559-584.

Chan, W., \& Chunn, D. (2014). Racialization, crime and criminal justice in Canada. Toronto, ON: University of Toronto Press.

Closs, W \& Mckenna P. (2006). Profiling a problem in Canadian police leadership: the Kingston Police data collection project. Canadian Public Administration, 49(2), 143-160. 
Comack, E. (2012). Racialized Policing: Aboriginal People's Encounters with the Police. Halifax, N.S: Fernwood Pub.

Corbeil, L. (2014, May, 8). 'Racist' Brampton flyer broke no laws, police say. The Toronto Star, Retrieved from: https://www.thestar.com/news/gta/2014/05/08/racist brampton_flyer broke no laws po lice say.html

Cross, J. (2016, August, 10). Why the Toronto Star's Landmark Carding Project Might Not Be Possible Today. Torontoist, Retrieved from: https://torontoist.com/2016/08/why-itwould-be-tougher-for-the-toronto-star-do-its-carding-data-foi-today/

Das, V. (2007). Life and Words: Violence and the Descent Into the Ordinary. Berkeley, CA: University of Californai Press.

Deal, C. (2011). FAITH OR FLIGHT?: A RELIGIOUS DILEMMA. Journal of Air Law \& Commerace, 76, 525-558

Dhamoon, R. (2013). EXCLUSION AND REGULATED INCLUSION. Sikh Formations: Religion, Culture, Theory, 9(1), 7-28.

Dhillon, S. (2007). The Sikh Diaspora and the Quest for Khalistan: A Search for Statehood or for Self-preservation? The Institute of Peace and Conflict Studies. New Delhi: Institute of Peace and Conflict Studies

DiCicco-Bloom, B. \& Crabtree, B. (2006). The qualitative research interview. Medical Education, 40(4), 314-321. DOI: 10.1111/j.1365-2929.2006.02418.x

Emerson, R., Fretz, R., and Shaw, L. (2011). WRITING ETHNOGRHAPIC FIELDNOTES: SECOND EDITION. Chicago, USA; The University of Chicago Press.

Epp, C., Haider-Markel, D., and Maynard-Moody, S. (2014). Pulled Over: How Police Stops Define Race and Citizenship. Chicago, USA: The University of Chicago Press.

Erlingsson, C. and Brysiewicz, P. (2017). A hands-on guide to doing content analysis. African Journal of Emergency Medicine, 7, 93-99. DOI: 10.1016/j.afjem.2017.08.001

Ewick, P. and Silbey, S. (1995). Subversive Stories and Hegemonic Tales: Toward a Sociology of Narrative. Law and Society Review 29: 197-226.

Foucault, M. (1975). Discipline and Punish. New York City, USA: Vintage Books.

Flood, J (2005). Socio-Legal Ethnography. In R. Banakar \& M. Travers (Eds.), Theory and Method in SocioLegal, (pp. 33-48), Oxford: Hart Publishing.

Flyvbjerg, B. (2006). Five Misunderstandings About Case-Study Research. Qualitative Inquiry, 12(2), 219-245.

Gill, P. S. (2014). A DIFFERENT KIND OF DISSIDENCE: THE GHADAR PARTY, SIKH HISTORY AND THE POLITICS OF ANTICOLONIAL MOBILIZATION. Sikh Formations, 10(1), 23-41. 
Glover, K. (2009). Racial Profiling: Research, Racism, and Resistance. Lanham, Maryland: Rowman \& Littlefield Publishers, Inc.

Goff, P. \& Kahn, K. (2012). Racial Bias in Policing: Why We Know Less Then We Should. Social Issues and Policy Review, 6(1), 177-210. DOI: 10.1111/j.1751-2409.2011.01039.x

Gorbunova, L., Ambrasat, J., \& Von Scheve, C. (2015). Neighborhood Stereotypes and Interpersonal Trust in Social Exchange: An Experimental Study. City \& Community, 14(2), 206-225. Doi: 10.1111/cico.12112

Grewal, H. (2010). WHO DESIRES THE RHINOCEROS? PROSAIC POETICAL AND MNEMONIC VISUAL REFRACTIONS OF VIOLENCE IN THE WAKE OF OPERATION BLUE STAR. Sikh Formations: Religion, Culture, Theory, 6(2), 193-219. Doi: 10.1080/17448727.2010.530514

Grewal, S. (2015, June, 12). Peel police chief says practice similar to carding takes place there. The Toronto Star, Retrieved from: https://www.thestar.com/news/gta/2015/06/12/peelpolice-chief-says-practice-similar-to-carding-takes-place-there.html

Grewal, S. (2015, October, 8). Peel Police don't mirror community's racial makeup, data shows. The Toronto Star, Retrieved from: https://www.thestar.com/news/city_hall/2015/10/08/peel-police-dont-mirrorcommunitys-racial-makeup-data-shows.html

Groenewald, T. (2008). Memos and memoing. In L. M. Given (Ed.), The SAGE encyclopedia of qualitative research methods (pp. 506-506). Thousand Oaks, CA: SAGE Publications, Inc. Doi: 10.4135/9781412963909.n260

Gubrium, J., \& Holestein, J. (2001). Handbook of Interview Research: Context and Method. Thousand Oaks, CA: Sage Publications, Inc.

Heyink, J. \& Tymstra, TJ. (1993). The function of qualitative research. Social Indicators Research, 29(3), 291-305. Doi: 10.1007/BF01079517

Hier, S. \& Walby, K. (2006). Competing analytical paradigms in the sociological study of racism in Canada. Canadian Ethnic Studies Journal, 38(1), 83-104. DOI:

Holmberg, L. (2003). Policing Stereotypes: A Qualitative Study of Police Work in Denmark. Berlin: Galda \& Wilch.

Hsieh, H.-F., \& Shannon, S. E. (2005). Three Approaches to Qualitative Content Analysis. Qualitative Health Research, 15(9), 1277-1288.

Jakobsh, D. \& Walton-Roberts, M. (2016). A century of miri piri: securing Sikh belonging in Canada. South Asian Diaspora, 8(2), 167-183.

Jakobish, D. (2014). The Sikhs in Canada : Culture, Religion, and Radicalization. In Bramadat, P. \& Dawson, L. (Eds.), Religious Radicalization and Securitization in Canada and Beyond (164-200). Toronto, ON: University of Toronto Press. 
Jameson, J. (2013). E-Leadership in higher education: The fifth "age" of educational technology research. British Journal of Educational Technology, 44(6), 889-915. doi: $10.1111 /$ bjet. 12103

Johnston, H. (2014). The Voyage of the Komagata Maru: The Sikh Challenge to Canada's Colour Bar, Expanded And Fully Revised Edition. Vancouver, BC: UBC Press.

Johnston, H. (2005). Sikhs in Canada. In Encyclopedia of Diasporas Immigrant and Refugee Cultures Around the World, 1075- 1083.

Johnson, R. (2006). Race and police reliance on suspicious non-verbal cues. Policing: An International Journal of Police Strategies \& Management, 30(2), 277-290.

Judge, P. (2003). Social Construction of Identity in a Multicultural State: Sikhs in Canada. Economic and Political Weekly 38 (17), 1725-1731.

Kaur, H. (2009). DIASPORIC SIKH ORGANISATIONS. The Indian Journal of Political Science, 70 (4), 1085-1098.

Krippendorff, K. (1980). Content Analysis: An Intrduction to Its Methodology. Beverly Hills, CA: Sage Publications, Inc.

Krupanski, M., Park, A.R., Melodia, L., Charney, C., Hamper, K., Paragas, B., ... Warren, V. (2009). Racial Disparity in NYPD Stops-and-Frisks: THE CENTER FOR CONSTITUTIONAL RIGHTS PRELIMINARY REPORT ON UF-250 DATA FROM 2005 THROUGH JUNE 2008. New York, NY: Center for Constitutional Rights.

Kunda, A. (1994). The Indian Armed Forces' Sikh and Non-Sikh Officers' Opinions of Operation Blue Star. Pacific Affairs, 67(1), 46-69.

Larochette, A.C., Murphy, A., \& Craig, W. (2010). Racial Bullying and Victimization in Canadian School-Aged Children: Individual and School Level Effects. School Psychological International, 31(4), 289-409

Larrabee, M. J., Weine, S., \& Woollcott, P. (2003). "The Wordless Nothing": Narratives of Trauma and Extremity. Human Studies, 26(3), 353-382.

Lum, Z. (2017, July, 20). Jagmeet Singh Explains How His Federal Racial Profiling Ban Could Actually Work. Huffpost. Retrieved from: http://www.huffingtonpost.ca/2017/07/20/jagmeet-singh-racial-profiling-ban-NDPleadership a 23038350/

Kaur, H. (2012). Reconstructing the Sikh Diaspora. International Migration, 50(1), 129-142. Doi: $10.1111 / \mathrm{j} .1468-2435.2010 .00656 . \mathrm{x}$

Kennedy-Macfoy, M. (2013). 'It's important for the students to meet someone like you.' How perceptions of the researcher can affect gaining access, building rapport and securing cooperation in school-based research. International Journal of Social Research Methodology, 16(6), 491-502. DOI: 10.1080/13645579.2013.823294

Mann, I. (2014). Immigrant Minorities under Canadian Multiculturalism: A Study of Sikh and Muslim Communities, Post-9/11. International Studies, 51(1-4), 145-161. 
Mann, R. (2017). Media framing and the myth of religious violence: The othering of sikhs in The Times of India. Sikh Formations: Religion, Culture, Theory, 12(2-3), 120-141.

Mcneill, P., and Chapman, S. (2im005). Research methods: third edition. New York, NY: Routledge Taylor \& Rancis Group.

McLean, C., \& Campbell, C. (2010). Locating Research Informants in a Multi-ethnic Community: Ethnic Identities, Social Networks, and Recruitment Methods. Ethnicity \& Health, 8(1), 41-61. DOI: 10.1080/13557850303558

Meng, Y. (2017). Profiling minorities: Police stop and search practices in Toronto, Canada. Human Geographies, 11(1), 5-23. DOI: 10.5719/hgeo.2017.111.1

Mortan, H. F. (2015). Investigating Detention and Street Checks. In M.E. Beare, N. Des Rosiers, \& A. C. Deshman (Eds.), Putting The State On Trial: The Policing of Protest during the G20 Summit (pp. 168-195). Vancouver: UBC Press.

Merrian, S. (2009). Qualitative Research: A Guide to Design and Implementation. San Francisco, CA: Jossey Bass.

Murji, K \& Solomos, J. (2005). Racialization in Theory and Practice. In Murji, K., \& Solomos, J., RACIALIZATION: Studies in Theory and Practice. (pp. 1-28). Oxford: Oxford University Press.

Murphy, K. (2009). Public Satisfaction With Police: The Importance of Procedural Justice and Police Performance in Police-Citizen Encounters. THE AURSTRALIAN AND NEW ZEALAND JOURNAL OF CRIMINOLOGY, 42(2), 159-178. DOI: 10.1375/acri.42.2.159

Nachiappan, K. (2017, November, 20). With Singh, a new chapter for Canada-India relations. Retrieved From: https://www.opencanada.org/features/singh-new-chapter-canada-indiarelations/

Nayak, A. (2005). White Lives. In Murji, K., \& Solomos, J., RACIALIZATION: Studies in Theory and Practice. (pp. 141-163). Oxford: Oxford University Press.

Nayak, A. (2007). Critical Whitness Studies. Sociology Compass, 1(2), 737-755. DOI: 10.1111/j.1751-9020.2007.00045.x

Nayar, K. (2004). The Sikh Diaspora in Vancouver: Three Generations Amid Tradition, Modernity, and Multiculturalism. Toronto, ON: University Of Toronto Press.

Nijhawan, M. \& Arora, K. (2013). LULLABIES FOR BROKEN CHILDREN': DIASPORIC CITIZENSHIP AND THE DISSENTING VOICES OF YOUNG SIKHS IN CANADA. Sikh Formations Religion, Culture, Theory, 9(3), 299-321. DOI: 10.1080/17448727.2013.861696

O'Conner, C. (2008). Citizen attitudes toward the police in Canada. Policing: An International Journal of Police Strategies \& Management, 31(4), 578-595. DOI: 10.1108/13639510810910571

Ontario (2016). Reg. 58/16: Collection of Identifying Information in Certain Circumstances Prohibition and Duties. Retrieved 
https://www.ontario.ca/laws/regulation/r16058?_ga=1.261110029.1238231610.14718101 $\underline{65}$

Owusu-Bempah, A. and Wortley, S. (2014). Race, Crime, and Criminal Justice in Canada. The Oxford Handbook of Ethnicity, Crime, and Immigration, 1-27. DOI: 10.1093/oxfordhb/9780199859016.013.020

Policy \& Politics. (2016, September, 23). Carding Debate | Desmond Cole Vs. Joe Warmington | Stop \& Frisk Toronto [Video File]. Retrieved from: https://www.youtube.com/watch?v=V-H_e3dDMwY\&t=62s

Pariona, A. (2017, April 25) Countries With The Largest Sikh Populations. worldatalas. Retrieved from: https://www.worldatlas.com/articles/countries-with-the-largest-sikhpopulations.html

[Policy \& Politics]. (2016, Sep, 23). Carding Debate | Desmond Cole Vs. Joe Warmington | Stop \& Frisk Toronto [video file]. Retrieved from: https://www.youtube.com/watch?v=VH_e3dDMwY

Potter, G. \& Kappeler, V. (2012). Introduction: Media, Crime, and Hegemony. The Harms of Crime Media: Essays on the Perpetuation of Racism, Sexism and Class Stereotypes, 3-17.

Puar, J. (2008). 'THE TURBAN IS NOT A HAT': QUEER DIASPORA AND PRACTICES OF PROFILING. Sikh Formations Religion, Culture, Theory, 4(1), 47-91.

Razack, S. (2017). The Impact of Systemic Racism on Canada's Pre Bombing Threat Assessment and Post-Bombing Response to the Air India Bombings. In Dean, A., Chakraborty, C., \& Failler, A., Remembering Air India: the art of public mourning. Edmonton: The University of Alberta Press.

Rankin, J. (2016). Award-winning law student denied cop ride-along — despite no criminal record. The Toronto Star, Retrieved from: https://www.thestar.com/news/gta/2016/06/28/lawyer-activist-denied-cop-ride-alonglaunches-dual-complaints.html

Rankin, J., Quinn, J., and Shepard, M. (2002, October, 19). Singled out. The Toronto Star, Retrieved from https://www.thestar.com/news/gta/knowntopolice/2002/10/19/singledout.html

Rankin, J., and Winsa, P. (2012, March, 9). Known to police: Toronto police stop and document black and brown people far more than whites. The Toronto Star, Retrieved from: https://www.thestar.com/news/insight/2012/03/09/known to police toronto police stop and document black and brown people far more than whites.html

Redlawsk, D., Tolbert, C., Mcneely, N.A. (2014). Symbolic Racism and Emotional Responses to the 2012 Presidential Candidates. Political Research Quarterly, 67(3): 680-694.

Rieti, J. (2016). Black Lives Matter Toronto rips new police street check policy. 
Roberts, J. and Doob, A. (1997). Race, Ethnicity, and Criminal Justice in Canada. Crime \& Just 21, 469-522. CBC News, Retrieved from: http://www.cbc.ca/news/canada/toronto/blmtopolice-carding-1.3856619

Roberts, J. and Stalans, L. (1997) Public Opinion, Crime and Criminal Justice. Boulder, CO: Westview Press.

Sandhu, G. (2018). AN UNCOMMON ROAD: HOW CANADIAN SIKHS STRUGGLED OUT OF THE FRINGES AND INTO THE MAINSTREAM. Vancouver, BC: ECHO Storytelling Agency.

Sandhu, J. (2016). WSO WELCOMES ONTARIO BAN ON CARDING. World Sikh Organization. Retrieved from: http://www.worldsikh.org/wso_welcomes_ontario ban_on_carding

Seshia, Maya. (2107). From Foreign to Canadian: Air India and the Ongoing Denial of Racism. In Dean, A., Chakraborty, C., \& Failler, A., Remembering Air India: the art of public mourning. Edmonton: The University of Alberta Press.

Shagrir, L. (2017). Journey to Ethnographic Research. Cham, Switzerland: Springer International Publishing AG.

Showmaker, D. (2010). THEORIES OF DELINQUENCY: AN EXAMINATION OF EXPLANATIONS OF DELINQUENT BEHAVIOUR. Oxford, UK: Oxford University Press.

Sian, K. (2017). Surveillance, Islamophobia, and Sikh Bodies in the War on Terror. Islamophobia Studies Journal, 4(1), 38-52.

Singh, B. (2013). THE CONCERN FOR NATIONAL SECURITY: THE IMPACT ON SIKH CANADIANS. Canadian Bar Review, 92(1), 49-56.

Singh, B. (2015). New Turban Screening Procedure at Canadian Airports Discriminatory: WSO. World Sikh Organization. Retrieved From: http://www.worldsikh.org/new_turban_screening_procedure_at_canadian_airports_discri minatory_wso

Singh, J. (2009). I ACCUSE... The Anti-Sikh Violence of 1984. New Delhi: Penguin Group.

Singh, J. [theJagmeetSingh]. (2017, Jul 13). Racial profiling is violent and systemic yet the halls of power in Canada remain silent. I won't. Here's why: [Tweet]. Retrieved from https://witter.com/thejagmeetsingh/status/885552808350674944?lang=en

Smith, M., \& Alpert, G. (2007). Explaining Police Bias. Criminal Justice and Behaviour, 34(10), 1262-1283.

Skocpol, T. (1987). Social History and Historical Sociology: Contrasts and Complementaries. Social Science History, 11(1), 17-30.

Statistics Canada. (2011). 2011 National Household Survey: Data tables. Retrieved from: http://www12.statcan.gc.ca/nhs-enm/2011/dp-pd/dt-td/Rpeng.cfm? $\mathrm{LANG}=\mathrm{E} \& A \mathrm{PATH}=3 \& \mathrm{DETAIL}=0 \& \mathrm{DIM}=0 \& \mathrm{FL}=\mathrm{A} \& \mathrm{FREE}=0 \& \mathrm{GC}=0 \& \mathrm{GID}=$ 
$0 \& \mathrm{GK}=0 \& \mathrm{GRP}=0 \& \mathrm{PID}=105399 \& \mathrm{PRID}=0 \& \mathrm{PTYPE}=105277 \& \mathrm{~S}=0 \& \mathrm{SHOWALL}=0 \& \mathrm{~S}$ $\underline{\mathrm{UB}}=0 \&$ Temporal $=2013 \& \mathrm{THEME}=95 \& \mathrm{VID}=0$

Steele, C. (1997). A threat in the air: How stereotypes shape intellectual identity and performance. American Psychologist, 52(6), 613-629.

Tatla, D. (1999). The Sikh Diaspora: The Search For Statehood. London, UK: UCL Press.

Tatla, D. (2006). The morning after: Trauma, memory and the Sikh predicament since 1984. Sikh Formations: Religion, Culture, Theory, 2(1), 57-88.

Tator, C \& Henry, F. (2006) Racial Profiling in Canada: Challenging the Myth of "a Few Bad Apples." Toronto: University Of Toronto Press.

Tavory, I., \& Timmermans, S. (2009). Two cases of ethnography: Grounded theory and the extended case method. Ethnography, 10(3), 243-263

[The Agenda with Steve Paikin]. (2015, Jun 12). To Card or Not To Card [video file]. Retrieved from: https://www.youtube.com/watch? $\mathrm{v}=\mathrm{f} 4 \mathrm{KcpXaMxtY \& t=471 \textrm {s }}$

Theobald, C. (2016, September, 20). Anti-immigration posters target turbans on University of Alberta campus. Edmonton Journal, Retrieved from: http://edmontonjournal.com/news/crime/anti-immigration-posters-target-turbans-onuniversity-of-alberta-campus

Timmermans, S., \& Tavory, I. (2012). Theory Construction in Qualitative Research From Grounded Theory to Abductive Analysis. Sociological Theory, 30(3), 167-186.

Todd, D. (2009). Sikh religion viewed unfavorably in B.C. Vancouver Sun. Retrieved from: https://vancouversun.com/news/staff-blogs/sikh-religion-viewed-unfavorably-in-b-c

Tulloch, M. (2018). Report Of The Independent Street Checks Review. Toronto, ON: Queen's Printer for Ontario.

Tulloch, M. (2017). Report Of The Independent Police Oversight Review. Toronto, ON: Queen's Printer for Ontario.

Turgo, N. (2012). 'I Know Him So Well': Contracting/tual 'Insiderness', and Maintaining Access and Rapport in a Philippine Fishing Community. Sociological Research Online, 17(3), 1-13. DOI: $10.5153 /$ sro.2660

Walby, K. and Larsen, M. (2012). Access to Information and Freedom of Information Requests: Neglected Means of Data Production in the Social Sciences. Qualitative Inquiry, 18(1), $31-42$.

Wilson, William Julius, and Anmol Chaddha. (2010). The Role of Theory in Ethnographic Research. Ethnography 10(4): 549-564.

World Sikh Organization. (n.d.). WHAT IS THE KIRPAN? Retrieved from: http://www.worldsikh.org/what_is_the_kirpan 
Wortley, S. (2003). Hidden Intersections: Research on Race, Crime, and Criminal Justice in Canada. Canadian Ethnic Studies, 35(3), 99-117.

Wortley, S. \& Owusu-Bempah, A. (2009). Unequal Before the Law: Immigrant and Racial Minority Perceptions of the Canadian Criminal Justice System. Int. Migration \& Integration 10, 447-473. DOI 10.1007/s12134-009-0108-x

Verma, R. (2006). TRAUMA, CULTURAL SURVIVAL AND IDENTITY POLITICS IN A POST-9/11 ERA: REFLECTIONS BY SIKH YOUTH. Sikh Formations: Religion, Culture, Theory, 2(1), 89-101.

Zuhair, K. \& McAndrew, B. (2005). Soft target the real story behind the Air India disaster. Toronto, ON: James Lorimer \& Company Ltd., Publishers. 